University of Rhode Island

DigitalCommons@URI

Open Access Master's Theses

2000

\title{
An Assessment of Decisional Balance, Self Efficacy, and Condom Stages of Change Among White and Minority Women
}

Shirley Amanda Gazabon

University of Rhode Island

Follow this and additional works at: https://digitalcommons.uri.edu/theses

\section{Recommended Citation}

Gazabon, Shirley Amanda, "An Assessment of Decisional Balance, Self Efficacy, and Condom Stages of Change Among White and Minority Women" (2000). Open Access Master's Theses. Paper 1653.

https://digitalcommons.uri.edu/theses/1653

This Thesis is brought to you for free and open access by DigitalCommons@URI. It has been accepted for inclusion in Open Access Master's Theses by an authorized administrator of DigitalCommons@URI. For more information, please contact digitalcommons-group@uri.edu. 
AN ASSESSMENT OF DECISIONAL BALANCE, SELF EFFICACY, AND CONDOM STAGES OF CHANGE AMONG

WHITE AND MINORITY WOMEN

BY

SHIRLEY AMANDA GAZABON

A THESIS SUBMITTED IN PARTIAL FULFILLMENT OF THE REQUIREMENTS FOR THE DEGREE OF

MASTERS OF ARTS

IN

PSYCHOLOGY

THE UNIVERSITY OF RHODE ISLAND

2000

49402 


\begin{abstract}
Between 1992 and 1999, the number of persons living with AIDS increased in all
\end{abstract} groups of women in the United States. In terms of ethnicity, the number of African American and Hispanic American infected with HIV has increased tremendously. In order to address the HIV pandemic among ethnic women in the United States, systematic methods for studying condom use and HIV prevention are being developed and validated.

The Transtheoretical Model (TTM) has been postulated as an integrative and comprehensive model of intentional behavior change that incorporates process oriented variables in an effort to predict how and when people adopt healthy behaviors. The purpose of this study is to assess the effectiveness of the decisional balance and selfefficacy constructs of the TTM in predicting condom stage of change for white and minority women. Much research has been done applying the TTM to white populations, but little has been done to apply this model to minority women. Because HIV/AIDS is such a prevalent disease among these groups and because there are cultural and ethnic differences among these groups, assessing the effectiveness of this model between white and minority women is essential.

In this study, it was hypothesized that most women would be in earlier condom stages of change or not ready to use condoms. Decisional balance and self-efficacy variables were also hypothesized to differ based on stage and ethnicity when predicting condom stage. Furthermore, Transtheoretical variables (decisional balance and selfefficacy) were hypothesized to predict over and above demographic characteristics.

A subsample of 340 women at risk for HIV were selected from a pool of 816 sexually at-risk New England Community who had participated as part of a longitudinal 
study. The ethnic distribution consisted of whites $(n=170)$, African Americans $(n=77)$, Native Americans ( $n=10)$, Asian Americans $(n=25)$, Hispanic Americans $(n=29)$, and other non-whites (29). The results of a Chi square test indicated a greater proportion of women in the earlier stages ( $44 \%$ in precontemplation and $20 \%$ in contemplation) than in later stages ( $6 \%$ in action and $16 \%$ in maintenance). Furthermore, an ethnicity by stage chi-square revealed a greater percentage of white women $(53 \%)$ than minority women $(37 \%)$ in the precontemplation stage. Moreover, a greater percentage of minority women $(18 \%)$ than white women $(10 \%)$ were in the preparation stage.

One-way ANOVAS indicated that pros, cons, and self-efficacy differ based on stage. Tukey HSD tests revealed that the lower the pros and self-efficacy the less readiness to use condoms. Two-way ANOVAS revealed that white and minority women's pros and self-efficacy did not differ based on stage. Standard multiple regression revealed that pros, cons, and self-efficacy predicted $21 \%$ of the variance in condom stage accounting. Hierarchical multiple regressions on the Transtheoretical variables indicated that they accounted for $17 \%$ of the variance for the total sample, $20 \%$ of the variance for the white subsample, and $15 \%$ of the variance for the minority subsample over and above demographics.

These results indicate that Transtheoretical variables, including decisional balance and self-efficacy are predictive of stage of change for white as well as for minority women. Discussion of how these variables might be incorporated into interventions aimed at increasing condom use in minority women, as well as limitations of the study are discussed. 


\section{ACKNOWLEDGEMENT}

I feel immensely indebted to all the committee members for contributing their time and knowledge throughout this research endeavor. Specifically, Lisa Harlow, Ph. D. for making this valuable data set available to me and contributing lots of her great statistical knowledge, Abram Salazar, Ph. D. for contributing his knowledge in communicating and studying ethnic minorities, and Kerry Evers, Ph. D. for her insight on the Transtheoretical Model based on her previous work using this data set. In particular, I would like to recognize my major professor, Patricia Morokoff, Ph. D. for her extraordinary guidance and wisdom throughout this process. I am also very grateful to Janet Evans, M.A. for all her help throughout this research thesis.

Most importantly, I would like to acknowledge my family and friends in Florida for always welcoming me with open arms after many months of hard work on this thesis. In particular, I would like to give special appreciation and dedicate this to Angel and Rosa Gazabon, my brother, Elot Gazabon, and my aunt Antonia Utria that through their hard work and perseverance have supported, inspired, and motivated me to be the person I am today. 


\section{PREFACE}

This thesis compares the decisional balance, self-efficacy, and condom stages of change constructs among white and minority women. It is prepared in manuscript format. 
ABSTRACT ii iv

PREFACE v

TABLE OF CONTENTS vi

LIST OF TABLES viii

LIST OF FIGURES ix

INTRODUCTION 1

JUSTIFICATION OF THE PROBLEM 3

Ethnic Considerations 3

Ethnic and TTM Variables assessed 7

Stages of Change 10

Decisional Balance 12

Self-efficacy 13

HYPOTHESES 14

METHOD 15

Participants 15

Labeling of Ethnicity 16

Materials 17

Procedure 19

RESULTS 20

General Demographic Analyses 20

Stage Distribution and Demographics 23 
Stages of Change

Predictors of Condom Stage of Change 28

DISCUSSION 31

So What? 39

Recommendations 40

Limitations 42

Staging Algorithm 45

Decisional Balance Scale 46

Self-Efficacy Scale 49

Demographic Scale 51

List of Tables 53

List of Figures 69

Bibliography 76 


\section{LIST OF TABLES}

Table 1: Demographics for Whites and Minorities

Table 2: Condom Stage Distribution

Table 3: Descriptive Statistics and Cronbach's Alphas on all Scales

Table 4: Intercorrelations Between Decisional Balance Pro Variables

For Minority Subsample

Table 5: Intercorrelations Between Decisional Balance Con Variables

For Minority Subsample

Table 6: Transtheoretical Variables and Minorities/Stage Distribution

Table 7: The Pros of Decisional Balance

Table 8: The Cons of Decisional Balance

Table 9: Self-Efficacy

Table 10: ANOVA Summaries for Condom Stages of Change, Pros, Cons,

Self-efficacy, and Ethnicity

Table 11: Means, Standard Deviations, and Sample Size of the Pros,

Cons, and Self- efficacy by Condom Stage of Change

Table 12: Standard Multiple Regressions Results for Prediction

Of Condom Stage

Table 13: Hierarchical Multiple Regression \# 1

Table 14: Hierarchical Multiple Regression \# 2

Table 15: Hierarchical Multiple Regression \# 3 


\section{LIST OF FIGURES}

Figure 1: Ethnic Distribution of Condom Stage

Figure 2: Ethnic Distribution of Pros Within Each Condom Stage

Figure 3: Ethnic Distribution of Cons Within Each Condom Stage

Figure 4: Ethnic Distribution of Self-Efficacy Within Each Condom Stage

Figure 5: Means for Pros and Cons Across the Condom Stages

Figure 6: Means for Self-efficacy Across the Condom Stages 


\section{INTRODUCTION}

During the past decade, there has been a dramatic increase in the rates of HIV and AIDS cases in the United States. According to Centers for Disease Control (1999), up until June of 1999 a total of 711,344 persons with AIDS were reported. Of these, $83 \%$ were men, $16 \%$ were women, and $1 \%$ were children less than 13 years of age. More astounding is that the annual rate of deaths due to AIDS has decreased while the number of persons living with AIDS continues to increase (Centers for Disease Control, 1998).

At one point, the disease affected predominately educated, White, middle class, gay men. However, the late 1990's witnessed a dramatic change of persons affected. Between 1992 and 1999, the number of persons living with AIDS increased in all groups of women living in the United States. Women accounted for $13.8 \%$ of the AIDS cases in 1992, compared to $23 \%$ in 1999 (Centers for Disease Control, 1999). Furthermore, although African American and Hispanic women make up only $21 \%$ of all the U.S. population of women, approximately $77 \%$ of the adult HIV infected cases include African American and Hispanic women (Centers for Disease Control, 1999). These findings reflect the seriousness of the problem and suggest that effective strategies to promote safe sex are urgently needed for minority women.

In order to address the HIV pandemic in the United States, systematic methods for studying HIV prevention and condom use are being developed and validated. The Transtheoretical Model is examined in this study because of its history of intervening upon behavior change for a number of health related behaviors (Prochaska \& DiClemente, $1983 ; 1984 ; 1985)$. The Transtheoretical Model (TTM) has been postulated as an integrative and comprehensive model of intentional behavior change that 
incorporates process oriented variables in an effort to predict how and when people adopt healthy behaviors. The model incorporates the decisional balance and self-efficacy constructs to predict a person's stage of change (Velicer et al., 1985, 1990). In the area of HIV prevention, the model has been extensively studied and supported (Redding \& Rossi, 1989, 1998; Grimley et al., 1993, 1995, 1996; Harlow et al., 1999; Evers et al., 1998). More research is needed to test the model among members of different ethnic groups who engage in a diverse range of HIV high-risk behaviors to determine if it is effectively predicting stage of change across ethnic groups.

The purpose of this study is to assess the effectiveness of the decisional balance and self-efficacy constructs of the Transtheoretical Model for predicting condom stage of change for minority women and White women. Much research has been done applying the Transtheoretical Model of behavior change to White populations, but little has been done to assess this model between an equal number of White and minority women. Particularly, a longitudinal study that also examined the effectiveness of the Transtheoretical variables using the current data set included $84 \%$ of the White subsample and $16 \%$ of the minority subsample (Evers et al., 1998). Because HIV/AIDS is such a prevalent disease among these groups and because there are cultural and ethnic differences among these groups, it essential to assess the effectiveness of this model for White and minority women. In an effort to create HIV prevention interventions relevant to the group of minorities, it is important to understand the predictors of readiness to use condoms. This study will address how decision-making variables such as condom pros and condom cons predict a woman's readiness to use condoms. In addition, it will also focus on how self-efficacy or confidence for condom use predicts a woman's readiness to 
use condoms. The application of the constructs to these two groups of women will allow us to determine if the model can be generalized to two distinct populations. In this study, a woman's readiness to use condoms will be determined by the Transtheoretical Model's condom stage of change.

This study represents a secondary data analysis of a large longitudinal study that examined predictors of condom use (Harlow et al., 1992). The data to be analyzed for this study represents only the first time point of the longitudinal study (time 2 and 3 assessed the same variables). This time point will be used for this study because it contains the largest number of minority women, thereby providing greater power to test the hypotheses.

\section{Justification of the Problem}

\section{Ethnic Considerations}

Although gay men still account for more cases of AIDS (57\%) than any other category (Centers for Disease Control, 1999), AIDS does not solely affect men. In fact, there has been a disproportionate increase of AIDS/HIV among women in the U.S. In 1992, AIDS became the fifth leading cause of death among women 15-44 years of age (Centers for Disease Control, 1993). A year later in 1993,16\% of the 100,000 cases of AIDS reported for US adults and adolescents were women (Centers for Disease Control, 1994). In addition, of the 79,674 persons older than 13 years of age diagnosed with AIDS in $1994,18 \%$ were women, which is nearly three times greater than the proportion of women diagnosed with AIDS in 1985 (Centers for Disease Control, 1994). More recent data shows that women account for $32 \%$ of the adult cases of HIV infection reported from July 1998 to June 1999 (Centers for Disease Control, 1999 
The risk of becoming infected with HIV/AIDS is not equally distributed among persons in the United States. In terms of ethnicity, through 1998 in the United States, $22 \%$ of women with AIDS were White, $57 \%$ were African American, and 20\% were Hispanic (Centers for Disease Control, 1998). When base rates for these ethnicities are taken into account, Hispanic females living in the United States are 7 times more likely to have AIDS, and African American females living in the United States are 13 times more likely to have AIDS, than White females (Centers for Disease Control, 1998). Furthermore, during 1998, the rate of AIDS cases among White women was 2.4 per 100,000 , whereas in African American women it was 49.8 per 100,000, and in Hispanic women it increased by 16.6 per 100,000 (Centers for Disease Control, 1998). In terms of exposure category, up until June of $1999,47 \%$ of Latina women were exposed through heterosexual contact and $41 \%$ were exposed through use of injection drugs (Centers for Disease Control, 1999).

Even though condom use has been shown to prevent HIV infection, research has demonstrated a lack of condom use among women at-risk for HIV/AIDS. In a study examining sexual behavior of women living in inner city low income housing, approximately one third of these women reported not using condoms in more than two thirds of intercourse occasions with partners who were having sex with other people (Sikkema et al., 1996). Moreover, a study found that $45.3 \%$ of African American women reported that their sexual partners never used condoms on any sexual occasion over the previous 3 months (Wingwood \& DiClemente, 1998).

In an effort to decrease HIV\AIDS transmission among women sexually at-risk, models have been developed aimed at changing women's condom use behavior. Models 
that have been applied to increase condom use include: Health Belief Model (Rosenstock et al., 1994), Social Learning Theory (Bandura, 1994), Aids Risk Reduction Model (Catania et al., 1990), the Multifaceted Model of HIV Risk (Harlow et al., 1993; 1998), and the Transtheoretical Model (Prochaska et al., 1992). The Transtheoretical Model is appealing because it offers an integrative framework for investigating how and why people change a problem behavior. It has been successfully applied to several areas of health behavior change including: smoking cessation, quitting cocaine, high fat diets, exercise adoption, mammography screening, sun protective behaviors, and condom adoption (Prochaska et al., 1994).

In order to increase condom use among minority women, models that predict minority women's readiness to use condoms are urgently needed. Research on the Transtheoretical Model for condom use has successfully been normed on and applied to mostly White women by White researchers (Redding \& Rossi, 1989, 1998; Grimley et al., 1993, 1995, 1996; Harlow et al., 1999; Evers et al., 1998). One can conclude from this research the effectiveness of predicting White women's condom stage of change. However, studies have demonstrated that ethnicity plays a major role when assessing a women's readiness to use condoms. According to Bowen and Trotter (1995), there were differences in stages of change as a function of ethnicity. In their study, White individuals were more likely to be in the action stage and less likely to be in the contemplation stage as compared to African Americans. Furthermore, Hispanics were more likely to be in the in the contemplation stage than African Americans. These findings suggest that in order to increase adoption and continuation of condom use across ethnic groups, assessments and interventions of culturally specific attitudes about condom use across cultural groups 
are important considerations (Amaro, 1995). Therefore, it seems imperative to assess the predictive ability of the Transtheoretical Model among the group of White and minority women at risk for HIV. Because the Transtheoretical Model has been developed among White samples and because there are culturally specific attitudes about condom use among minorities, it is possible that the current Transtheoretical measures may result in less ability to predict.

In order to test the efficacy of the Transtheoretical Model for different ethnic groups, this study will evaluate the ability of Transtheoretical Model variables to account for variance beyond that accounted for by demographic variables among minority and White women. The demographic variables to be evaluated are age, education, income, job, ethnicity, marital status, number of sex partners, type of sex partner, living arrangement, type of sex partner, number of pregnancies, number of children, and relationship length (with most recent sex partner). The aim of this study is to assess equal groups of White and minority women at the first time point in a longitudinal study. A past naturalistic study using all 3-time points in this data set focused on the relationship between demographic variables and condom stage of change in the White subsample of women who participated. Evers et al. (1996a), using $84 \%$ of the White subsample in the current data set, found that women with more than high school education were 2 to 3 times more likely to progress to a higher stage of change during the longitudinal study than women with only a high school education or less. Furthermore, Evers et al., (1996b) also found that Transtheoretical variables (decisional balance, self-efficacy, and processes) were successful at predicting condom stage of change for a predominately White $(96 \%)$ college student sample. 
In addition, when comparisons of the strength of the prediction in demographic versus Transtheoretical variables (decisional balance, self-efficacy, and processes) have been made, Transtheoretical variables (decisional balance, self-efficacy, and processes) have been shown to be stronger predictors (Wilcox et al., 1985; Prochaska et al., 1985). For example, a study on predictors of smokers' success found that individuals at the higher income and educational levels were more likely, following a relapse, to try to abstain from cigarettes (Wilcox et al., 1985). In the area of smoking cessation, Prochaska et al., (1985) also found Transtheoretical variables (decisional balance, self-efficacy, and processes) to be the most efficacious at predicting smoking stage of change.

\section{Ethnic and TTM Variables Assessed:}

Ethnicity. One purpose for comparing White and minority women is to investigate possible cultural differences in relation to readiness to use condoms. According to consumer studies, American women purchased approximately $40 \%$ of the condoms sold, an increase of $15 \%$ since the discovery of AIDS (Battle, 1986). This picture is not consistent with the behaviors of ethnic women, particularly those who are poor or less behaviorally directed by Euro-American culture (Mays \& Cochran, 1988). Given the sharp increase in heterosexually transmitted HIV among African American and Latina women in the United States, this population represents an understudied subgroup at increased risk of HIV infection (Mays \& Cochran, 1988). Thus, identifying some of the psychosocial, educational, attitudinal, and gender related factors associated with this population's decision making and self-efficacy may be useful, not only to determine the ability to predict condom stage of change, but also in developing more efficacious HIV prevention interventions. 
In terms of condoms and HIV, African American and Latina women are at an attitudinal and educational disadvantage when compared to White women. One study looking at AIDS related attitudes in African American and Latina women found that both groups of women had more negative attitudes towards condoms than their White counterparts (Nyamathi et al., 1993). In addition, many African American and Latina women are not aware that they are at risk, and have many misconceptions regarding HIV transmission and the effectiveness of condoms (Land, 1994). Moreover, research has found that less educated Latina women had lower self-efficacy to discuss condoms, to manage partner resistance, to use condoms with regular partners, and to control impulses than White woman (Van Oss et al., 1998).

Most minority women perceive AIDS as a low concern when compared to the hierarchy of other risks in their lives and the existence of resources available to act differently (Mays \& Cochran, 1988; Kalichman et al., 1992). In other words, for women who often realistically feel powerless to change the external realities of their lives, such as how much they earn and/or of finding financial supplements, AIDS may be the least of their worries.

The sexual division of labor explains how African American women's socioeconomic impoverishment enhances their sexual vulnerability to HIV. Researchers have demonstrated that constrained economic resources of many low-income African Americans may force them to place low priority on purchasing condoms compared with their competing demands, such as paying their rent and caring for their children. Moreover, low levels of literacy may limit many African American women's ability to 
access information on HIV prevention strategies, including condom use (Wingwood et al., 1998).

A cultural factor that makes it difficult for Latina women to reduce HIV infection are cultural norms that define appropriate behavior and regulate gender roles. The idealized gender roles of machismo and marianismo are complementary and opposite. According to Raffaelli and Suarez Al-Adam (1998), the idealized gender role of machismo relates to men who are considered strong, rational, and independent while the idealized gender role of marianismo relates to women who are thought of as submissive, sentimental, and dependent. In addition, Simoni et al., found that for Spanish speaking Latinas the cultural norms of simpatia (an emphasis on smooth interpersonal relationships) and familism (an emphasis on the family as the primary social support) may have inhibited disclosure of their HIV-positive status to family members and lovers. Moreover, the sexual double standard results in dichotomization of women into "good" and "bad", with "good" women being disinterested in sex and ignorant of sexual matters and "bad" women being sexually available and knowledgeable. Therefore, Latina women who attempt to introduce condoms into a relationship may be going against traditional gender roles, which are specified by the culture, in several ways, including defying the male prerogative of controlling family members' behavior and exhibiting knowledge about, and interest in, sexual behavior.

Although minority women with HIV come from various cultural backgrounds, they share many common issues and concerns. For one, it has been suggested that they have a collectiveness mentality rather than an individualistic mentality. Minority women's sexual behavior has been described as related to distal cultural forces, 
expectations, social norms, as well as specific situational factors (Amaro, 1995). Where as individualistic mentality focuses on the power of the person to make his/her choices independently of others, collective mentality focuses on the power of outside forces to influence his her/choices. Therefore, minority women may see themselves, not independent of, but in relation to their families, churches, and community. In addition, gender roles as well as cultural values and norms at least influence, and sometimes define, the behavior of men and women and the interpersonal relationships in which sexual behavior occurs (Amaro, 1995). For minority women, this often means less power in relationships and a context that socializes them to be passive sexually and in other ways (Amaro, 1995).

Stages of Change. According to the Transtheoretical Model of behavior change, individuals who change their behavior go through a process involving progress through a series of five stages (Prochaska \& DiClemente, 1982, 1983, 1984, 1985; Prochaska \& Velicer, 1997). The stage of change construct implies that change occurs over time and in a cyclical rather than a linear pattern (Prochaska \& DiClemente, 1982). In this model, people move from the precontemplation stage (not intending to change), to contemplation stage (intending to change within the next six months), to the preparation stage (actively planning to change), to the action stage (overtly making changes for less than six months), and to the maintenance stage (maintaining change for more than six months).

Research done looking at stages of change has recognized that individuals differ in terms of their readiness to change their behavior (Prochaska et al., 1997). Moreover, this research has demonstrated that the majority of the people are in the precontemplation or contemplation stage. However, most health behavior change programs have been 
developed for individuals who are prepared to take action (Prochaska et al., 1997). According to the Transtheoretical Model, interventions could be more efficacious and cost effective when they are matched to individual stages (Prochaska et al., 1997).

The Transtheoretical Model's stages of change have been validated in the area of sexual behavior (Harlow et al., 1999; Grimley et al., 1993, 1995). In the area of contraceptive and condom use adoption and maintenance, college men and women's stage of change followed a predicted pattern, with those that had more negative attitudes in the earlier stages of readiness to change and less ready to practice safer sex activities (Grimley et al., 1995). In addition, Grimley et al., (1993) found that college students seemed more ready to use contraceptive methods (condoms and birth control) for pregnancy prevention as compared to STD prevention. Additional supports for differences in readiness to use condoms were revealed in a study assessing condom use in a high-risk sample. According to Harlow et al., (1999), a total of $51 \%$ of individuals at risk for HIV were in the precontemplation stage. Most importantly, research results using the Transtheoretical stages of change with the current data set (Harlow et al., 1992) found that women who where in low to moderate risk for HIV and also those women who where very sexually active tended to report greater readiness for, and, more positive attitudes towards using condoms than other women, particularly for minority subsamples (Harlow et al., 1998). Moreover, a study using these data also analyzed longitudinal changes in stages and found that $62.5 \%$ of the sample remained in the same stage of change over 1 year, $17.5 \%$ regressed at least one stage, and $20 \%$ progressed at least one stage (Evers et al., 1998). 
Decisional Balance. According to decision-making theory, decision-makers construct a "balance sheet" of gains and losses (Janis \& Mann, 1977). This decisionmaking process of weighing the pros and cons of changing behavior varies depending on where a person is on the continuum of stages of change (Prochaska \& DiClemente, 1984; Prochaska et al., 1994b). The decisional balance construct of the TTM suggests that people emphasize the perceived negative aspects of behavior change in the precontemplation stage, whereas they emphasize the positive aspects in the maintenance stage. The crossover between the pros and the cons, particularly tested with smoking cessation, is said to occur during the contemplation stage (Prochaska et al., 1994b). The effectiveness of this construct in predicting the stages of change has been demonstrated across 12 problem behaviors (Prochaska et al., 1994b). This research suggests that people emphasized the cons of the healthy behavior at earlier stages of change and the pros of the healthy behavior increased as they progressed through the stages.

This construct has been validated by studies that have applied decisional balance to condom and contraceptive use (Galavotti et al., 1995; Grimley et al., 1993, 1996). According to Grimley et al., (1993), the decisional balance construct demonstrated to be a consistent and stable measure that can be used when comparing pros and cons or assessing attitudes and behaviors toward condom use among heterosexual populations at various risk for HIV (Grimley et al., 1993). Grimley et al., (1996) found that the cons of condom adoption outweighed the pros for individuals in the precontemplation stage and the pros outweighed the cons in the maintenance stage. Furthermore, in a sample of 390 college students, researchers developed the pros and cons for safer sex across four 
different safer sex behaviors and found support for the two factor structure (Pros/Cons) of decisional balance (Redding et al., 1989; Redding \& Rossi, 1998).

Self-Efficacy. According to Social Cognitive Theory (Bandura, 1977), confidence in one's ability to perform a behavior is highly related to actual ability to perform that behavior. Within the Transtheoretical Model, a measure of this construct consists of rating the degree of confidence one has in performing a behavior (Bandura 1977;

Prochaska et al., 1997). Self-Efficacy has also been shown to be related to the stages of change (Velicer et al., 1990). For example, smokers in the precontemplation stage had the lowest self-efficacy score, where those in maintenance reported the highest self-efficacy (DiClemente et al., 1985).

The self-efficacy construct has also been validated in the area of sexual behavior (Galavotti, et al., 1995; Grimley et al., 1996; Redding \& Rossi, 1998; Riley et al., 1993). According to a study that investigated the relationship between condom and contraceptive self-efficacy scores and the stages of change among women, the condom and contraceptive self-efficacy scores were significantly different across the stages and increased from the precontemplation to the maintenance stage (Galavotti et al., 1995). Grimley et al., (1996) found the self-efficacy measure to be a reliable and stable factor when assessing condom use among a heterosexual population. Redding and Rossi (1998) have also demonstrated how the Transtheoretical Model can be applied to general situational self-efficacy for safer sex. According to this study, participants differentially rated their confidence in predicting safe sex and their temptation to have unsafe sex among five situations. Another study examining self-efficacy for contraceptive and condom use in women at risk for HIV found that women in the precontemplation stage 
had lower levels of perceived self-efficacy for each method of prevention assessed, as compared to those further along the stages of adoption (Riley et al., 1993).

\section{Major Hypotheses}

The following are the major hypotheses for the present study:

\section{Stages of Change:}

1. A greater proportion of women will be in the earlier stages of change (precontemplation and contemplation) or not intending to use condoms within six months or more than women in the later stages of change (action and maintenance).

2. Women will demonstrate significantly lower pros in the earlier stages of condom use (precontemplation and contemplation) than in the later stages.

3. Women will demonstrate significantly lower cons in the later stages of condom use (action and maintenance) than in the earlier stages (action and maintenance).

4. Women will demonstrate significantly lower self-efficacy scores regarding condom use in the earlier stages (precontemplation and contemplation) than in later stages of change (action and maintenance).

Ethnic:

5. The ethnic subgroups in the minority subsample will not differ in terms of their condom stage, pros, cons, and self-efficacy.

6. White women will have more pros towards condoms and thereby will be in later stages of change (action and maintenance) than minority women.

7. White women will have higher self-efficacy scores towards condoms and thereby will be in later stages of change (action and maintenance) than minority women. 


\section{Transtheoretical:}

8. Among the whole sample, pros and cons towards condoms, and self-efficacy towards condoms will predict condom stage of change.

9. Among White women, pros and cons towards condoms as well as self-efficacy towards condoms will predict condom stage of change.

10. Among minority women, pros and cons towards condoms as well as self-efficacy towards condoms will predict condom stage of change.

11. Based on hypothesis 8 and 9 , minority women will have less variance accounted for when predicting stage of change.

12. Transtheoretical variables (decisional balance, self-efficacy, and processes) will predict condom stage of change over and above demographic variables in the full sample.

13. Among White women, Transtheoretical variables (decisional balance, self-efficacy, and processes) will predict over and above demographic variables.

14. Among minority women, Transtheoretical variables (decisional balance, self-efficacy, and processes) will predict over and above demographic variables.

\section{Method}

\section{$\underline{\text { Participants }}$}

This study represents a secondary data analysis of approximately 816 women sexually at risk for HIV who were recruited from a New England Community in 19931994, as part of a naturalistic longitudinal study (see Harlow et al., 1998). The women were eligible to participate if they had engaged in one or more of the following in the past five years: two or more sexual partners, a sexual partner who injected drugs using a 
needle, or a sexual partner who had other sexual partners. The eligibility criteria ensured that participants experienced some type of sexual risk for HIV. Additionally, women in this study were required to be 18 years of age or older, and not intending to become pregnant. Although data in the longitudinal study were collected at 3 time points, this study will examine the data from the first time point only. In order to select the sample to be used in this study, the sample of minority women $(n=170)$ was selected from the total number of women who participated $(n=816)$. Then, from the remaining White women $(n=646), 170$ White women were randomly selected in order to have an equal subsample in which to compare the outcomes. Therefore, the ethnic composition of this sample consisted of 170 White women and 170 minority women, the latter of which includes African Americans $(n=77)$, Hispanics $(n=29)$, Asian Americans $(n=25)$, Native Americans $(n=10)$, and other non-Whites $(n=29)$.

\section{Labeling of Ethnicity}

For this study, the terms White and minority have been chosen for several reasons. For one, the terms are familiar to many researchers that are interested in this area. These terms can easily be located for literature searches and they are also consistent with Center for Disease Control Surveillance report categories. In addition, the demographic measure in this study, which assessed race, included the term "White" as a response option for women who were filling out the survey (Harlow et al., 1992). Therefore, in order to maintain consistency between the response option and the woman's choice of classification, the term "White" seems to be the most appropriate to describe that particular group. Furthermore, the term "minority" was chosen to represent the group of African Americans, Hispanic Americans, Asian Americans, Native Americans, and 
other non-Whites that participated in this study. The term "minority" is familiar to the members of this group and it is consistently used by the media, researchers, and the community organizations that serve these group members. Therefore, group members might easily identify and relate to this term as opposed to using less familiar terms. For example, the term "women of color" might be problematic because it is not sensitive to those women who identify themselves as "White" Hispanic. This example might also apply to the other groups of women that perhaps do not see themselves as a person of color. Therefore, because this group is mixed and familiar with the term "minority" and can relate to this label it seems to be the most appropriate and least offensive classification tool.

\section{Materials}

Measures for this study were drawn from a larger study conducted on women atrisk for HIV (Harlow et al., 1992). For specific list of measures see pages 45-51.

Demographics. Participants were asked a set of questions to determine their age, education, income, job, ethnicity, marital status, number of sex partners, whether they had a regular sex partner, living arrangement, type of sex partner (male or female), number of pregnancies, number of children, and length of a relationship. These questions identify and characterize the sample.

Stages of Change. Participant's stage of change was be determined by a stage algorithm. This algorithm consisted of two questions: "Do you use condoms", and "Do you plan to start always using condoms when you have sex?" The response for the first question were on a 5 point Likert scale ranging from 1 (never) to 5 (started using them 6 months or longer). The responses for the second question were also on 5 point Likert 
scale ranging from 1 (no) to 5 (already use condoms). Depending on the participant's responses, they were placed in their respective stage of change (precontemplation, contemplation, preparation, action, or maintenance; also see Appendix on page 24). The participant's staging is done for the purpose of characterizing the sample in terms of their readiness to adopt condom use. Cronbach's alpha for these scales has been reported at .90 , indicating good internal consistency (Prochaska et al., 1990).

Decisional Balance. Decisional Balance was measured using a 16-item scale with 8 items each to assess perceived pros and cons. The scale began with this statement: "If you were going to use a condom, how important would these things be?'. An example of a pro statement is, "It will build trust between partners". An example of a con statement is, "Sex has to be planned". Respondents answer on a five point Likert scale ranging from 1 (not all-important) to 5 (very important). Cronbach's alpha has been reported at .81 for the pros and .83 for the cons (Prochaska et al., 1990).

Self-Efficacy. Condom self-efficacy was measured using a 6-item scale that measured the core construct of self-efficacy (Redding \& Rossi, in press; Redding et al., 1996). The confidence construct included the question "How sure are you that a condom or latex barrier would be used for sex in these situations". Examples of items are statements such as "When I am really turned on" and "When my partner gets mad about wearing a condom". Participants answered items in a Likert scale format that ranged from 1 (not at all sure) to 5 (very sure). Cronbach's alpha for these scales has been reported at .89 (Prochaska et al., 1990). 


\section{Procedure}

The procedure to collect this data was part of a 1993-1994 longitudinal study (Harlow et al., 1998). Three general strategies were used concurrently to recruit both White and minority women with HIV risk behaviors in an array of local populations. An effort was made to recruit minority women by acquiring voter registration lists in areas with a high concentration of minorities and by contacting newspapers and agencies specifically serving people of color $(n=170)$. In addition, women were recruited from the wider community though advertisements in newspapers and on radio and TV $(n=359)$. Furthermore, women who were enrolled at the adult college of continuing education campus of a New England university were sent a letter of invitation to participate if they met eligibility requirements $(n=287)$. After women called to express interest, they were mailed exclusion criteria for participation (see Participants section) and consent forms that were mailed back if they were qualified and agreed to participate. Then, the participants were sent a survey and asked to complete it in a private place. The incentives included a $\$ 5.00$ check for returning the consent form, and a chance to take part in a $\$ 250.00$ drawing for returning the survey. The survey took 1 hour or less to be completed. A four-digit code number was assigned to each woman, and was matched to a list of names and addresses. This was kept in a locked file with limited access to staff not engaged in data analysis, and needed for tracking responses across future survey administrations. Participants were provided with business size cards giving phone numbers and referrals to women's centers in the area and a toll free telephone number were they could reach a counselor or request further information, in case they needed them or felt distressed by the survey. 


\section{Results}

In order to determine the representative of the White subsample, t-tests and chisquare tests were used to compare the means of the White subsample of women in this study $(n=170)$ with the total remaining sample of White women $(n=646)$. The findings revealed no significant differences in the following demographic and Transtheoretical variables: type of job, relationship length, age, income, education, marital status, living arrangement, whether they had a regular sex partner, condom pros, condom cons, and condom use self-efficacy.

\section{General Demographics Analyses}

The general demographics for each sample are presented in Table 1. For the whole sample, the typical participant was aged $18-50(97 \%)$ with average age of 31 , had some college work (59\%), was unemployed (41\%), and was single (64\%). More than half of the sample was making less than 19,999 a year (58\%). Specifically, the average age for White participants was 31 compared to 28 in the minority sample, which is a significant difference. In addition, $52 \%$ of the White participants had some college work compared to $67 \%$ of the minority, which is a significant difference. Furthermore, $29 \%$ of the White participants were unemployed compared to $54 \%$ of the minority participants, which is a significant difference. Moreover, $58 \%$ of the White women were single compared to $70 \%$ of the minority women, which is not a significant difference. In terms of income, $41 \%$ of the White women were making less than $\$ 10,000$ compared to $75 \%$ of the minority women making this also a significant difference.

The sexual demographics for each sample are also presented in Table 1. More than half of the total sample had a man that they regularly had sex with (73\%). The 
majority of the sample indicated that they did not live with their sexual partner $(61 \%)$. The average length of the relationships was 3 years. In addition, the majority of the women (90\%) indicated having sex with a man during the past five years. Furthermore, more than half of the sample had no children (54\%) and had never been pregnant (38\%). Specifically, $69 \%$ of the White women had a man they regularly had sex with compared to $76 \%$ of the minority women, which was not significantly different. In addition, $62 \%$ were not living with their sex partner now compared to $60 \%$ of the minority women, which was not a significant difference. Furthermore, $93 \%$ of the White women were having sex mostly with men compared to $90 \%$ of the minority women, which was not a significant difference. Moreover, $62 \%$ of the White participants had no children when compared to $45 \%$ of the minority women, which is a significant difference. In terms of the number of pregnancies, $43 \%$ of the White women compared to $33 \%$ of the minority women had no pregnancies, which is a significant difference.

In terms of condom use, $14 \%$ of the sample indicated using condoms every time they had sex. In addition, $44 \%$ of the sample indicated never using condoms in the last 30 days, and $20 \%$ indicated using them sometimes (see Table 2). Among the White subsample, $10 \%$ of the sample indicated using condoms every time they had sex. Moreover, $53 \%$ of the White subsample indicated never using condoms in the last 30 days, and $18 \%$ indicated using them sometimes (see Table 2). Among the minority subsample, $18 \%$ of the sample indicated using condoms every time they had sex. In addition, $37 \%$ of the minority subsample indicated never using condoms in the last 30 days, and $21 \%$ indicated using them sometimes (see Table 2). 
Descriptive statistics on all scales can be seen in Table 3. The means, standard deviations, and Cronbach's alphas (reliabilities) were calculated for each scale within each subsample. With all scales using 5-point Likert scales, the sample had high pros towards using condoms $(M=3.94)$, low cons towards using condoms $(M=2.18)$, and a high self-efficacy/confidence towards using condoms $(M=3.37)$.

Cronbach's alphas were calculated on each scale to get an indication of the reliability of each scale and subscale for each subsample. All scales for each group were found to be reliable. For the total sample, the condom pro subscale had an internal consistency alpha coefficient of .76. More specifically, the condom pros subscale for the White subsample $(\alpha=.80$ ) had a somewhat higher reliability when compared to the condom pros subscale for the minority subsample $(\alpha=.70)$. This indicates that the condom pro subscale for the White subsample of women is somewhat more reliable than the condom pro subscale for minority women. In addition, for the total sample, the condom con subscale had an internal consistency alpha coefficient of .78. More specifically, the condom cons subscale for the White subsample had a somewhat higher reliability ( $\alpha=.81$ ) when compared to the condom cons subscale for the minority subsample $(\alpha=.75)$. This indicates that the condom con subscale for the White subsample of women is somewhat more reliable than the con subscale for minority women (see Tables 3, 4, and 5). In addition, the condom self-efficacy scale for the total sample $(\alpha=.91)$, as well as for White $(\alpha=.91)$ and minority $(\alpha=.91)$ women demonstrated consistently high reliability (see Table 3 ).

Because the reliabilities of the pros and cons subscales were consistently higher for the White than the minority group, homogeneity of variance tests were conducted in 
order to compare the scales' reliabilities. For the condom pros, $\underline{F}(169,169)=1.14$ at $p>$. 05 , indicated that there is not enough evidence to conclude that the two reliability values were significantly different. For the condom cons, $\underline{F}(169,169)=1.08$ at $p>.05$, indicated that there was also not enough evidence to conclude that the two reliability values were significantly different.

\section{Stage Distribution and Demographics}

The first hypothesis stated that a greater proportion of women would be in the earlier stages of change (precontemplation and contemplation) or not intending to use condoms within six months or more, than women in later stages of change (action and maintenance). In order to test this hypothesis, a Chi square test, conducted with SPSS, revealed significantly different proportions of women across the stages, $(\chi 2(5)=10.79$, $\mathrm{p}<.03$ ). The analysis revealed that a greater proportion of women were in the earlier stages of change ( $44 \%$ in precontemplation and $20 \%$ in contemplation) than in later stages of change ( $6 \%$ in action and $16 \%$ in maintenance).

Furthermore, an ethnicity by stage Chi square test revealed significant ethnic differences across the stages of change for condom use. The analysis revealed that a significantly greater percentage of White women (53\%) than minority women (37\%) were in the precontemplation stage, $(\chi 2(5)=8.94, \mathrm{p}<.003)$. In addition, a significantly greater percentage of minority women (18\%) than White women $(10 \%)$ were in the preparation stage, $(\chi 2(5)=4.87, \mathrm{p}<.027)$.

\section{Transtheoretical Variables and Minorities}

In hypothesis 5 , it was proposed that the ethnic subgroups in the minority sample would not differ in terms of their condom stage, pros, cons, and self-efficacy. To test 
hypothesis 5 , an exploratory analysis, also conducted with SPSS, was analyzed with data from the whole sample $(n=340)$ in order to examine the degree of variability within the entire group. Because the entire sample is composed of different ethnic groups with different sample sizes, there might be too much variability within this sample. The exploratory analysis allowed us to determine the degree of homogeneity in the sample across condom stage, condom pros, condom cons, and self-efficacy.

The exploratory analysis graphs on the entire sample can be seen on Figures 1,2, 3, 4. The means, standard deviations, and sample sizes were converted into t-scores and calculated for each scale (See Tables 6, 7, 8,9). With all scales using five-point Likert scales, the sample analysis revealed that most participants were within the earlier stages of change (precontemplation and contemplation). For the condom pro subscale, the tscore mean revealed that each ethnic group was within one standard deviation from the mean. For the condom con subscale, the t-score mean revealed that each ethnic group was within one standard deviation from the mean. In particular, African Americans and the other/non-Whites had unusually relative elevated mean score in the action stage when compared to others in that stage and when compared across other stages (precontemplation, contemplation, preparation and maintenance). For the condom selfefficacy subscale, the t-score mean revealed that each ethnic group also fell within one standard deviation from the mean. In particular, Asian Americans had unusually relative elevated mean score in the precontemplation stage when compared to others in that stage and when compared across other stages (precontemplation, contemplation, preparation and maintenance). Due to unequal sample sizes, caution when interpreting these findings is recommended. 
To further determine whether there were differences among groups in stage of change, as well as condom pros and cons, and condom self-efficacy within each stage of change, separate one-way and two-way ANOVAS were done with less discrepant sample sizes. A modified sample consisted of 77 Whites (selected randomly from the 170 White subsample), 77 African American, 25 Asian Americans, 29 Hispanic Americans, and 29 other non-Whites. Since the Native American group was small $(n=10)$, they were excluded. The total revised sample was $\mathrm{N}=247$. These modifications were made in order to make the sample size more similar, increasing the power of the ANOVA to detect differences.

In the one-way ANOVA, the findings revealed no significant differences in condom stage of change among Whites and minorities, $F(4,232)=.088, \mathrm{p}>.05$. In the two-way ANOVA's, the findings revealed non-significant interaction among White and minorities condom pros, $\mathrm{F}(4,16)=.728, \mathrm{p}>.05$; condom cons $\mathrm{F}(4,16)=.810, \mathrm{p}>.05$; and condom self-efficacy, $F(4,16)=.246, p>.05$. Therefore, these results also confirm the homogeneity assumption within a somewhat more equivalent sample size groups.

\section{$\underline{\text { Stages of Change }}$}

To test hypotheses 2, 3, 4, 6 and 7, one-way and two-way ANOVAS were used according to procedures described by Tabachnick and Fidel (1996). Follow up Tukey HSD tests revealed where there were mean differences. Standard deviations and sample sizes are reported in Table 10. All means are reported on Table 11.

Results of the one-way ANOVAS can be seen in Table 10. In hypothesis 2, we proposed that women would demonstrate significantly lower condom pros in the earlier stages of condom use (precontemplation and contemplation) than in the later stages. A 
one-way ANOVA using condom stage as the IV with 5 levels (precontemplation, contemplation, preparation, action, and maintenance) and condom pros (DV) revealed that women significantly differed in the pros of condom use based on what condom stage they were in. A follow up Tukey HSD test revealed that the condom pros in the precontemplation stage significantly differed from the condom pros in the preparation, action and maintenance stages. In this case, the condom pros were lower in the precontemplation stage and higher in the preparation, action and maintenance stages. In hypothesis 3 , it was proposed that women would demonstrate significantly lower condom cons in later stages of condom use (action and maintenance) than in earlier stages (precontemplation and contemplation). A one-way ANOVA using condom stage as the IV with 5 levels (precontemplation, contemplation, preparation, action, and maintenance) and condom cons (DV) revealed that women significantly differed in the cons of condom use based on what stage they were in. A follow-up Tukey HSD test revealed the condom cons in the precontemplation and contemplation stage significantly differed from the condom cons in the maintenance stage. In this case, the condom cons were higher in the precontemplation and contemplation stages and lower in the maintenance stage. In hypothesis 4 , it was proposed that women would demonstrate significantly lower selfefficacy scores regarding condom use in the earlier stages (precontemplation and contemplation) than in later stages of change (action and maintenance). A one-way ANOVA using condom stage as the IV with 5 levels (precontemplation, contemplation, preparation, action, and maintenance) and condom self-efficacy (DV) revealed that women significantly differed on condom self-efficacy based on what stage they were in. A follow-up Tukey HSD test revealed that the condom self-efficacy scores in the 
precontemplation, contemplation, and preparation stage significantly differed from the condom self-efficacy scores in the action and maintenance stages. In this case, the condom self-efficacy scores were lower in the precontemplation, contemplation, and preparation stages and lower in the action and maintenance stages. A plot of the means for each Transtheoretical condom decisional balance and condom self-efficacy scales allowed further examinations of the findings (see Figures 5 and 6).

In hypothesis 6, it was proposed that White women would have more pros towards condoms and thereby would be in later stages of change (action and maintenance) than minority women. To test hypothesis 5, a two-way ANOVA using ethnicity (IV 1) with two levels (White and minority), condom stage as (IV 2) with 5 levels (precontemplation, contemplation, preparation, action, and maintenance), and condom pros (DV) revealed a non-significant interaction among White and minority women's condom pros based on what stage they were in (Table 10). A further analysis of the main effects revealed significant differences in the condom pros based on condom stage, but no significant differences in condom pros based on ethnicity. In hypothesis 7 , it was proposed that White women would have higher condom self-efficacy scores towards condoms and thereby will be in later condom stages of change (action and maintenance). A two-way ANOVA using ethnicity (IV 1) with two levels (White and Minority), condom stage as (IV 2) with 5 levels (precontemplation, contemplation, preparation, action, and maintenance), and condom self-efficacy (DV) revealed a non-significant interaction among White and minority women's condom self-efficacy based on what condom stage they were in. A further analysis of the main effects revealed significant 
differences in condom self-efficacy based on condom stage, but no significant differences in condom self-efficacy based on ethnicity.

\section{Predictors of Condom Stage of Change}

In order to test hypotheses 8,9 , and 10 , standard multiple regressions analyzed which independent variables (pros, cons, and self-efficacy) were the strongest predictors of condom stage of change (DV) for the total sample $(n=340)$ and for each group of women ( $n=170$ White women and $n=170$ minority women). If the multiple $R$ was significant, the importance of included predictors could be determined by assessment of standardized beta weights (b's). The higher the absolute value of the standardized weights, the stronger the predictor. The sign (+ or -) will determine the direction of the effect. The interpretation of the regression output was also assessed using correlations between the independent and dependent variable(s).

In hypothesis 8, we proposed that among the whole sample, pros and cons towards condoms as well as self-efficacy towards condoms would predict condom stage of change. To test hypothesis 8 , all the Transtheoretical variables (pros, cons, and selfefficacy) were entered at once using the entire sample $(n=340)$. The multiple correlation was significant, $\mathrm{R}=.44, \underline{\mathrm{F}}(3,339)=27.47, \mathrm{p}<.001$. The three Transtheoretical variables accounted for $20 \%$ of the variance in predicting condom stage of change.

In hypothesis 9, it was proposed that among the White subsample, pros and cons towards condoms as well as self-efficacy towards condoms would predict condom stage of change. To test hypothesis 9, Transtheoretical variables (pros, cons, and self-efficacy) were entered at once using the White subsample $(n=170)$. The multiple correlation was 
significant, $R=.43, \underline{F}(3,166)=12.74, p<.001$. The three Transtheoretical variables accounted for $19 \%$ of the variance in predicting condom stage of change.

In hypothesis 10 , it was proposed that among the minority subsample, pros and cons towards condom as well as self-efficacy towards condoms would predict condom stage of change. To test hypothesis 10, all the Transtheoretical variables (pros, cons, and self-efficacy) were entered into the equation at once using the minority subsample ( $\mathrm{n}=$ 170). The multiple correlation was significant, $\mathrm{R}=.45, \underline{\mathrm{F}}(3,166)=13.80, \mathrm{p}<.001$. The three Transtheoretical variables accounted for $20 \%$ of the variance in predicting condom stage of change. The results of the standardized beta weights (b's) can be seen in the Table 12.

Based on the results of hypothesis 9 and 10, in hypothesis 11 it was proposed that minority will have less variance accounted for when predicting condom stage of change. The results indicate that the Transtheoretical variables (condom decisional balance and self-efficacy) accounted for $19 \%$ of the variance for the White women and $20 \%$ of the variance for the minority women when predicting condom stage of change. Contrary to the hypothesis, the results do not reveal that minority women have less variance accounted for when predicting condom stage of change.

Furthermore, to test hypotheses 12,13 , and 14, hierarchical multiple regressions were performed on the entire sample $(n=340)$ and on each subsample $(n=170)$ according to the procedures outlined in Tabachnick and Fidel (1996). In hierarchical multiple regression, the variables are entered in steps according to their theoretical importance. According to Tabachnick and Fidel (1996), the researcher has control over whether the 
items that enter first are the least or the most important. For the current study, the variables were chosen to enter in the following order:

Step 1- Demographics (race, age, education, job, income, marital status, length of relationship, regular partners, living arrangement, and type of partner), and Step 2- TTM Constructs (condom pros, cons, and self-efficacy).

In hypothesis 12, we proposed that Transtheoretical constructs would predict condom stage of change over and above demographic variables in the full sample. To test hypothesis 12 , using the entire sample $(n=340)$, the hierarchical multiple correlation was significant for step $1, \underline{\mathrm{F}}(11,297)=3.263 \mathrm{p}<.001$ with demographic variables accounting for $11 \%$ of the variance in predicting condom stage of change. In step 2 of this same analysis, the total $\mathrm{R} 2=.28, \underline{\mathrm{F}}(14,294)=7.97 \mathrm{p}<.001$, with Transtheoretical variables accounting for $17 \%$ of the variance in predicting condom stage of change, over and above that accounted for by demographics (see Table 13). In hypothesis 13 , it was proposed that Transtheoretical constructs would predict condom stage of change over and above demographic variables in the White subsample. To test hypothesis 13 , using the White subsample $(\mathrm{n}=170)$, the hierarchical multiple correlation was significant for step $1, \underline{E}(10,138)=1.47 \mathrm{p}>.158$, with the demographic variables accounting for $10 \%$ of the variance in predicting condom stage of change. In step 2 for this same analysis, the total $\mathrm{R} 2=.30, \underline{\mathrm{F}}(13,135)=4.42 \mathrm{p}<.001$, with the Transtheoretical variables accounting for $20 \%$ of the variance in predicting condom stage of change, over and above that accounted by demographics (see Table 14). In hypothesis 14, it was proposed that Transtheoretical constructs would predict condom stage of change over and above demographic variables in the minority subsample. To test hypothesis 14 , using the minority subsample $(n=170)$, 
the hierarchical multiple correlation was significant for step $1, \underline{F}(10,149)=2.03 p<$ .034 , with the demographic variables accounting for $12 \%$ of the variance in predicting condom stage of change. In step 2 of this same analysis, the total $\mathrm{R} 2=.27, \underline{\mathrm{F}}(13,146)=$ $5.27 \mathrm{p}<.001$, with the Transtheoretical variables accounting for $15 \%$ of the variance in predicting condom stage of change, over and above that accounted by demographics (see table 15).

Even though there was no specific hypothesis for the demographic characteristics predicting condom stage of change, the findings revealed that participant's demographics predicted condom stage of change for the total sample and for the minority subsample, but not for the White subsample. The best demographic predictors for the total sample were income and whether they had a regular sex partner or not. For both variables, the higher the income and having a regular sex partner, the lower the stage or readiness to use condoms. In the minority subsample, the best predictors were income and living arrangement. For both variables, the higher the income and living with a sex partner all the time, the lower the stage or readiness to use condoms (Please see table $13,14,15$ for all the demographic results).

\section{Discussion}

The primary objective of this study was to evaluate the role of the Transtheoretical variables in predicting condom stage of change among White and minority women. The most important finding revealed that for the entire sample and for each subsample (White and minority) the theoretical model of stages of change was effective in predicting woman's condom stage over and above their demographic characteristics. In the hierarchical multiple regression analysis, we found that 
Transtheoretical variables accounted for $17 \%$ of the variance for the entire sample, $20 \%$ of the variance for the White women, and $15 \%$ of the variance for the minority women over and above the participant's characteristics. Because woman's attitudes and confidence predicted readiness of condom use over and above her individual characteristics, this finding demonstrates that woman's readiness to use condoms can be directly assessed, and is open to intentional change. Because the Transtheoretical variables were not static or fixed (such as age, ethnicity, and income) but instead were amenable to change (such as attitudes and confidence), this finding supports the knowledge that readiness to use condoms can be assessed and intervened by considering the woman's positive and negative attitudes and confidence towards condom use (Wilcox, et al., 1985). Furthermore, a comparison of the degree of predictability attributed to each demographic and Transtheoretical variable revealed that condom selfefficacy was by far the strongest predictor of condom stage of change for all the women. These findings are supported by previous studies looking at Transtheoretical variables and stages of change in the area of smoking cessation and safer sex (Prochaska et al., 1985; Evers et al., 1996b). The practical implication of this important finding reveals that these predictor variables have the ability to change, are self-mediated, and can be maximized under self-control when designing HIV at-risk prevention programs. Most importantly, the Transtheoretical variables (condom pros, cons and self-efficacy) appear somewhat equally effective for White and minority women when predicting condom stage of change.

However, it should be noted that the demographic variables significantly predicted stage of change for the total group of women and for the minority group of 
women. For the total group of women, the higher the income and having a regular sex partner, the lower the stage or readiness to use condoms. For the minority group of women, the higher the income and living with a sex partner all the time, the lower the stage or readiness to use condoms. The practical implication of this important finding reveals that these predictor variables could possibly be influenced by the degree of partner perceived risk to STD/HIV that women may experience. Research on partner perceived risk and HIV prevention behaviors has found that women who perceive themselves more at-risk for STD/HIV are more motivated to initiate prevention behaviors (Hobfoll et al., 1990). In terms of the findings in this study, minority women with lower incomes, with no regular sex partner and that have that have no living arrangement with their sex partner, may perceive themselves more at risk for HIV and more ready to use condoms. Most importantly, the implications of these findings reveal that the minority women who may perceive themselves lower at-risk for STD/HIV with their partner may be putting themselves at-risk for not using condoms. Research on perceived risk has found that these women may be placing themselves at risk for HIV if the perceived levels of their partners are not accurate (Gangahedkar et al., 1997).

In addition to the findings that lent support to the Transtheoretical Model, the findings also indicate ethnic differences that challenge past assumptions about readiness to use condoms (condom stage of change) among White and minority women. Contrary to the literature (Bowen \& Trotter, 1995), more White (50.6\%) than minority (36.5\%) women were in the precontemplation stage or not intending to use condoms within the next six months. Furthermore, more minority $(18.2 \%)$ than White $(9.4 \%)$ women were in the preparation stage, or have been using condoms during the past 30 days. These 
findings support previous findings using this data set (Harlow et al., 1998) and suggest that for this particular sample minority women rather than White women were more ready to use condoms. The practical implications of these findings indicate a shift in minority women's readiness to use condoms. As suggested by Kane (1990) Kline, and Oken (1992), the traumas of poverty, addiction, and loneliness have pushed women out of prescribed roles such as worrying about the "good girl" or "bad girl" images or holding back communication about safe sex and this has had enormous impact on their behavior. A study that focused on understanding safer sex negotiation in a group of lowincome African American women found that African American women were able to achieve safer sex negotiation sporadically by using compliance gaining strategies such as bargaining, bullying, and autocratic methods (Margillo \& Imahori, 1998).

In terms of the condoms stages of change, the findings also support Transtheoretical research that individuals differ in terms of their readiness to change behavior (Prochaska, et al., 1997). Condom use differences were found based on the women's condom stage of change. The results revealed that the majority of women at risk of HIV/AIDS were in the earlier stages of change (43\% in precontemplation and 19.1 $\%$ in contemplation) or not intending to use condoms within six months or more, than women in the later stages of change (6.2\% in action and $15.3 \%$ in maintenance).

In regards to the decisional balance variables, the women in earlier stages of condom use (precontemplation and contemplation) demonstrated significantly lower condom pros than cons. Conversely, women in later stages of condom use demonstrated lower condom cons than pros. This inverse relationship between the condom pros and cons based on condom stage suggest that attitudes and behaviors towards condom use are 
different across the stages, with women at earlier stages having more negative attitudes towards condoms than women in later stages. These findings have been supported in previous research that has looked at the effectiveness of the condom pros and cons in predicting condom stage of change (Prochaska et al., 1994b).

In regards to the self-efficacy variable, women demonstrated significantly lower condom self-efficacy scores in the earlier stages (precontemplation and contemplation) than in the later stages of change (action and maintenance). This finding suggests that women in earlier stages of change experience less confidence in either using condoms themselves or getting a partner to use them. On the other hand, women in later stages tended to experience a higher level of confidence in either wearing condoms or having their partner wear it. These findings have been supported in prior research that has looked at self-efficacy for contraceptive and condom use in women at risk for HIV (Riley et al., 1993). All these findings suggest the utility of the condom stages of change, condom decisional balance, and condom self-efficacy for differentiating those who are effectively reducing risk for HIV exposure from those who are not.

In regards to the Transtheoretical variables (condom pros, cons, and self-efficacy) predicting condom stage of change for the whole group the results revealed that Transtheoretical variables were predictive of condom stage of change. This suggests that an individual's degree of positive and negative attitudes towards condom use along with the degree of confidence towards using condoms can predict the degree of readiness to use condoms. Furthermore, a specific look at the predictability of the Transtheoretical variables for each group of women revealed a similar pattern. For White women Transtheoretical variables accounted for $19 \%$ of the variance and for minorities they 
accounted for $20 \%$ of the variance. Furthermore, a comparison of the degree of predictability attributed to each Transtheoretical variable revealed that condom selfefficacy was by far the strongest predictor of condom stage of change for the entire sample. This finding suggests that a woman's condom self-efficacy serves as an important predictor of whether or not she will be ready to use condoms. These findings have been supported by previous research using the White sub-sample in this data set (Evers et al., 1996a).

A specific exploratory evaluation of the minority subsamples condom stage, condom decisional balance, and condom self-efficacy variables revealed a similar pattern of condom pros, cons, and self-efficacy scores across the different ethnic groups. This suggests that, even though the minority group was composed of different ethnicities, their scores were similar enough in order to establish a fair comparison. Furthermore, this finding allows us to generalize our results to a similar group of ethnic minorities.

Even though this research study has lent support for the Transtheoretical Model's strong track record for investigating the factors that influence sexual health behavior change, it is important to speculate why certain hypotheses were not supported. This study did not find significant differences in White and minority women's condom pros and condom self-efficacy scores. In addition, White and minority women's condom pros, cons, and self-efficacy did not significantly differ when predicting condom stage. There could be several explanations for why the expected differences were not found.

One explanation relates to the problems in individual participants' use of ethnic identifiers. Many psychologists tend to think of ethnicity as a categorical variable that is assumed to influence psychological outcomes or as a nuisance variable to be controlled. 
According to Phinney (1996), both ethnic categories and labels for these categories vary over time, context, and individuals. Furthermore, many researchers assert that these ethnic labels (Hispanic, non-Hispanic, White, African American, and Asian /Pacific Islanders) are "social" constructions rather actual labels that are out there in the world (Waters \& Eschbach, 1995). In fact, Phinney asserts that because of their dispersion and mixing with both mainstream American culture and with other ethnic groups in the United States, ethnic groups are not distinct entities, but rather a part of a diverse cultural mix. Furthermore, Phinney (1996) states that cultures are not static but continually evolving and changing. Therefore, considering that the labels in this study could potentially have within group variability, cultural blending, and are in constant change, it is hard to determine if ethnic minorities used in this study actually reflect the culture they are thought to represent.

The problem with ethnic labels can be illustrated using two examples from the literature on minority health. According to Flack et al., (1995), the ethnic label Asian/Pacific Islanders has tremendous diversity in language, culture, and geographic distribution. In fact, he states that these individuals differ immensely in terms of racial origin, religion, lifestyle, diet, and health. Furthermore, Amaro (1988) explains that the term "Hispanic" is an umbrella term for a group of people who have distinct historical, political, economic, and racial differences. In fact, she reports that the lack of Hispanic group identifiers is a serious drawback because patterns in epidemiology of AIDS suggests that some sub-groups of women may be at higher risks than others.

Another possible explanation is that if the Hispanic American or Asian American are highly acculturated, they may think and behave more like the White sample. 
According to Kline, Kline, and Oken, (1992), acculturation to the mainstream Anglo culture may be linked to increase in women's power in their personal relationships. In their study, Kline et al., (1992) found that acculturated Hispanic women who were injection drug users reported a high degree of power in their personal relationships and many reported being successful in persuading their partners to use condoms.

Furthermore, Bell and Alcalay (1997) found substantial knowledge gaps between acculturated and less acculturated poor Hispanic women. In their research, acculturated respondents had greater confidence in their abilities to acquire wellness-related information. Considering that acculturation wasn't measured in this study, it is possible that a lack of support for the hypotheses is due to a high acculturation level among the ethnic minorities who participated. This high acculturation level could make them more similar to the White population.

Another factor that might have contributed to the findings is the particular characteristics of this minority sample. This sample of ethnic minorities was recruited from advertisements in radio, TV, and newspaper (Harlow et al., 1998). Furthermore, some women were enrolled in an adult college of continuing education (CCE). Research in this area has found that highly educated people are more likely to adopt new health strategies due to their access to prevention programs promoted through the radio, TV, and newspaper (Catania et al., 1993). Therefore, it is possible that the results of this study reflect the impact of prevention programs aimed at certain socioeconomic groups and college campuses, rather than the general HIV at-risk community population.

In addition, Harlow et al., (1998), using this data set, also found greater readiness for and more positive attitudes toward condom use, particularly for the minority women. 
Relevant to previous and current findings, the minority women's sexual behaviors in this sample might not be representative of the minorities in the community. Contrary to the findings with this data set, Nyamathi et al., (1993) found that unsafe behaviors, such as having multiple partners, intravenous drug use, and unprotected sexual activity were common among Latina and African American women. Therefore, it is possible that the sexual behaviors and attitudes in this particular group might not be representative of the condom behaviors and attitudes of the women in the general public who are at-risk. $\underline{\text { So What? }}$

What can we conclude? Several themes emerged that have important implications for interventions aimed at increasing condom use and safer sexual behavior in a diverse group of women. First, women's attitudes and confidence toward condom use were shown to be important in whether that woman is using condoms or not. Condom pros, cons, and self-efficacy added over and above demographic characteristics when predicting condom stage of change. Most importantly, regardless of a woman's ethnicity, condom self-efficacy was shown once again to be an important predictor to condom use. Furthermore, women's readiness to use condoms, attitudes and confidence towards condoms varies by ethnicity. In this sample, minority women were more ready to use condoms within the next 30 days than White women. Moreover, more White women were not thinking of using condoms within the next six months when compared to the minority women. Women's pros, cons, and self-efficacy toward condom use were found to be different depending on the woman's stage of change (degree of readiness to use condoms). Secondly, a woman's attitudes and confidence towards condom use has been shown to be important in whether that woman chooses to use condoms or not. Regardless 
of ethnicity, woman's perceived pros, cons, and self-efficacy toward condom use were important predictors of condom stage of change or degree of readiness to use condoms. Interventions directed at woman at-risk for HIV/AIDS might focus on assessing the degree of positive and negative attitudes toward condom use along with the confidence in using condoms in order to determine the degree of readiness to use condoms. Interventions should move to increasing positive attitudes and confidence toward condom use in order for women to adopt safer sex practices. Finally, interventions might also focus on maintaining the behavioral confidence in one's ability to use condoms across different situations.

$\underline{\text { Recommendations }}$

Contrary to the expectations, regarding minority women being less ready to use condoms, our findings revealed that more White women at-risk for HIV are less ready to use condoms. Researchers applying the Transtheoretical Model to design HIV prevention programs should recognize that White women maybe less ready to use condoms.

Furthermore, it is important for researchers to oversample impoverished ethnic minorities at risk for HIV/AIDS (Nyamathi, et al., 1993) that may not have access to radio, TV, or newspaper.

Moreover, sexual behavior change models aimed at predicting readiness to use condoms need to include ethnic labels that capture the fluidity and the within group diversity of the different cultural groups. In particular, studies that include Hispanic American women in their sample need to consider that some groups of Hispanic women may be at higher risks than others. The Centers for Disease Control (1999) reported that highest numbers of women with AIDS are concentrated in the eastern area of the United 
States. The major Hispanic groups that reside in the east are Puerto Ricans, Dominicans, and Cubans (Amaro, 1988). Because the "Hispanic American" label does not specify Hispanic subgroup, it is not possible to discern in which Hispanic group women are most at-risk. Therefore, future research should abandon general categories and adopt specific ethnic identifiers in order to determine which Hispanic subgroups are most at risk. Furthermore, sexual behaviors and beliefs associated with those Hispanic subgroups that are most at-risk may be identified and considered when developing culturally appropriate HIV prevention models.

In addition, behavior change models need to include acculturation scales that will allow researchers to determine whether the ethnic groups adhere to the global descriptors used for the major American ethnic groups. Because Hispanic Americans and Asian Americans in the U.S. are continuously interacting with the American culture, these ethnic minority subgroups may have abandoned collectivist ideals and internalized American individualistic ideals in terms of their knowledge, attitudes, and behaviors regarding condom use. A study looking at the relationship between acculturation and $\mathrm{HV}$ risk among Hispanics showed that low acculturation tends to play a protective role because these women report fewer HIV risks, largely due to their more firm adherence of traditional cultural values, which tends to undermine self-initiated behavior (Romero et al., 1999). In contrast, more acculturated Latinas reported engaging in greater risky sexual behaviors in their relationships (Newcomb et al., 1998). Therefore, future research should examine the implications of acculturation status and condom use in ethnic minorities. 
In addition, future research in the area of HIV prevention should also consider differential risk factors of women who are in the precontemplation stage (not ready to use condoms in the next six months). For example, some women in precontemplation for condom use may consider themselves at low-risk of acquiring HIV/AIDS because they practice sexual monogamy without realizing that their male partner is either already infected or has other sexual partners. This would be particularly relevant for less acculturated women who believe to be "safe" because they are sexually monogamous. These women are at low risk of acquiring HIV/AIDS as far as their male partner is not infected with HIV/AIDS and realistically practices sexual monogamy also. Therefore, studies need to further explore acculturation and the differential risk factors, not only in women's sexual behavior, but also in their partner's sexual behavior.

Finally, researchers that are applying the Transtheoretical Model to predict readiness to use condoms among minority women should enhance the reliability of the decisional balance measure by changing items that may not be considered pros and cons for using condoms. Specifically, minority women might find pros more relevant if they included items that link behavior change to pride in one's culture and stresses the family responsibility to protect the children (Land, 1994), such as "I will protect my family" and "I will set an example in my community". Furthermore, minority women may also find cons more relevant if they included items that addressed the association of condoms with prostitution and poor hygiene, such as "My community will consider me a prostitute" and "My family will think less of me" (Land, 1994). 


\section{Limitations}

There are some limitations to this study. For one, this is a self-reported survey of sexual behavior. In self-reported surveys, there is always the possibility of memory inaccuracies and question or answer misinterpretations (Clark \& Schober, 1992, \& Loftus et al., 1992).

In addition, the study assesses sexual behavior at a given time point in a participants life. Since it is a cross sectional study, it does not reflect long lasting changes in a person's life like a longitudinal study would do. In other words, unless a longitudinal study were done, one can only say that a participants' decisional balance and self-efficacy scores can/cannot predict their condom stage of change at this given time point.

Furthermore, due to the oversampling of White, heterosexual, high school graduates and low-income women these findings may not be generalizable to female heterosexuals that do not share these demographic characteristics.

In addition, this study did not include Transtheoretical processeses of change measure partly because they weren't included in the survey from where this data was drawn (see Harlow et al., 1998). The Transtheoretical Model's processes measure, in the area of HIV prevention, has been validated and empirically tested by researchers interested in understanding stage transitions (Grimley et al., 1992; Redding \& Rossi, 1993). Prochaska et al., (1994) has been able to identify these overt and covert strategies used by people to modify diverse problem behaviors. Therefore, because this important aspect of the model was not included in this study, one cannot assess or conclude anything about the participants' time 1 processes in relation their stage nor can we guide the design for future interventions. 
Last of all, this was a convenience sample, and was not a random sample of women from the New England area. Therefore, this sample may not be an accurate reflection of the population at large. In addition, because the subsample of minority women $(n=170)$ is small and disproportional, analyzing ethnic group differences within this sample is not recommended. 


\section{Staging Algorithm}

Staging Questions:

1. Do you use condoms?

1. Never

2. Sometimes, but not always

3. Started always using 1 month ago.

4. Started always using 3-5 months ago.

5. Started always using 6 months ago or longer.

2. Do you plan to start always using condoms when you have sex?
1. No
2. Yes, within the next six months
3. Yes, within the next 30 days
4. Already always use condoms

Staging Algorithm:

(A) If for the first question they select 1 or 2 and for the second question they select 1 , then they are in precontemplation.

(B) If for the first question they select 1 or 2 and for the second question they select 2 , then they are in contemplation.

(C) If for the first question they select 1 or 2 and for the second question they select 3 , then they are in preparation.

(D) If for the first question they select 3 or 4 and for the second question they select 4 , then they are in action.

(E) If for the first question they select 5 and for the second question they select 4, then they are in maintenance. 
Question: Below are some reasons why some people do or do not use condoms. How important would these reasons be if you thought about using a condom? Think about how important they would be even if you do not use condoms. Circle your answer.

If you were going to use a condom, how important would these things be?

1. It would build trust between partners.

a. not at all important

b. a little important

c. somewhat important

d. fairly important

e. very important

2. It is a lot of trouble.

a. not at all important

b. a little important

c. somewhat important

d. fairly important

e. very important

3. I would feel more responsible.
a. not at all important
b. a little important
c. somewhat important
d. fairly important
e. very important

4. Sex has to be planned.
a. not at all important
b. a little important
c. somewhat important
d. fairly important
e. very important

5. Sex would feel safer.
a. not at all important
b. a little important
c. somewhat important
d. fairly important
e. very important

6. My partner might be angry.
a. not at all important
b. a little important 

c. somewhat important
d. fairly important
e. very important

7. I would not worry as much about getting pregnant.
a. not at all important
b. a little important
c. somewhat important
d. fairly important
e. very important

8. Sex is less exciting.
a. not at all important
b. a little important
c. somewhat important
d. fairly important
e. very important

9. I would not worry as much about getting AIDS.
a. not at all important
b. a little important
c. somewhat important
d. fairly important
e. very important

10. My partner might not want to have sex.
a. not at all important
b. a little important
c. somewhat important
d. fairly important
e. very important

11. My partner might respect me more.
a. not at all important
b. a little important
c. somewhat important
d. fairly important
e. very important

12. My partner might not like it.
a. not at all important
b. a little important
c. somewhat important
d. fairly important
e. very important 
13. It would protect my partner.
a. not at all important
b. a little important
c. somewhat important
d. fairly important
e. very important

14. My partner might make fun of me.
a. not at all important
b. a little important
c. somewhat important
d. fairly important
e. very important

15. Condoms are easy to get.
a. not at all important
b. a little important
c. somewhat important
d. fairly important
e. very important

16. My partner might think I play around.
a. not at all important
b. a little important
c. somewhat important
d. fairly important
e. very important 


\section{Self-Efficacy Scale}

Question: Think about yourself in the past 6 months. How sure are you that a condom or latex barrier would be used for safer sex in these situations? Please think about how you would even if you do not use condoms. Circle your best answer.

1. When I am really turned on.
a. not at all sure
b. a little sure
c. kind of sure
d. fairly sure
e. very sure

2. When my partner gets mad about wearing a condom.
a. not at all sure
b. a little sure
c. kind of sure
d. fairly sure
e. very sure

3. When I am depressed.
a. not at all sure
b. a little sure
c. kind of sure
d. fairly sure
e. very sure

4. When I have been drinking or doing drugs.
a. not at all sure
b. a little sure
c. kind of sure
d. fairly sure
e. very sure

5. When I am angry.
a. not at all sure
b. a little sure
c. kind of sure
d. fairly sure
e. very sure 
6. When I am afraid I might get AIDS.

f. not at all sure

g. a little sure

h. kind of sure

i. fairly sure

j. very sure 
Directions: For the first 15 questions, please circle the answer that is best for you or fill in the blanks. If you have comments or anything that you would like to add, please feel free to write them down next to the questions.

1. What is your race or cultural group?
a. White
b. African American
c. Native American
d. Asian American
e. Hispanic-American
f. Other

3. How old are you?

4. How long have you gone to school?
a. did not finish $8^{\text {th }}$ grade
b. grade $8-12$
c. graduated from high school
d. some college work
e. graduated from college
f. graduate degree or coursework

5. What is your job now?

6. How much money did you make last year?
a. less than $\$ 10,000$
b. $\$ 10,000$ to 19,999
c. $\$ 20,000$ to 34,999
d. $\$ 35,000$ to 50,000
e. over $\$ 50,000$

6. Are you married now?
a. single, never been married
b. married
c. separated or divorced
d. widowed

7. About how long have you been involved with your most recent sex partner? (fill in the blanks) years months weeks

8. About how many sex partners have you had in your life? 
9. Are you living with a sex partner right now?
a. no
b. sometimes, at least several days a month.
c. yes, all the time

10. In the past five years, when you had sex was it:
a. always with men?
b. mostly with men?
c. about half of the time with men?
d. mostly with women?
e. always with women?

11. Is there a man you regularly have sex with (husband or steady partner)?
a. no
b. yes

12. How many children do you have? (fill in)

13. How many times have you been pregnant? (fill in) 
Table 1

Demographics for Whites and Minorities

\begin{tabular}{|c|c|c|c|c|c|}
\hline \multirow[t]{2}{*}{ Variable } & \multicolumn{2}{|c|}{ White } & \multicolumn{2}{|c|}{ Minority } & \multirow{2}{*}{$\begin{array}{l}\text { Chi square/ } \\
\text { t distribution }\end{array}$} \\
\hline & $\mathrm{n}$ & percent & $\mathrm{n}$ & percent & \\
\hline Sample size & 170 & $50 \%$ & 170 & $50 \%$ & \\
\hline \multicolumn{6}{|l|}{ Ethnic breakdown } \\
\hline African Americans & -- & -- & 77 & $45 \%$ & \\
\hline Hispanic Americans & -- & -- & 10 & $6 \%$ & \\
\hline Asian Americans & -- & -- & 25 & $15 \%$ & \\
\hline Native Americans & -- & -- & 29 & $17 \%$ & \\
\hline Other non-whites & + & -- & 29 & $17 \%$ & \\
\hline Age & & & & & .002 \\
\hline $18-25$ & 65 & $38 \%$ & 87 & $51 \%$ & \\
\hline $26-35$ & 52 & $29 \%$ & 46 & $27 \%$ & \\
\hline $36-45$ & 39 & $23 \%$ & 27 & $16 \%$ & \\
\hline 46 or older & 16 & $10 \%$ & 10 & $6 \%$ & \\
\hline Income & & & & & .001 \\
\hline Less than $\$ 10,000$ & 70 & $41 \%$ & 126 & $75 \%$ & \\
\hline$\$ 10,000$ to $\$ 19,999$ & 41 & $24 \%$ & 27 & $16 \%$ & \\
\hline$\$ 20,000$ to $\$ 34,999$ & 50 & $29 \%$ & 14 & $8 \%$ & \\
\hline$\$ 35,000$ to $\$ 50,000$ & 8 & $5 \%$ & 2 & $1 \%$ & \\
\hline Over $\$ 50,000$ & 1 & $1 \%$ & 0 & $0 \%$ & \\
\hline Education & & & & & .001 \\
\hline Below $8^{\text {th }}$ grade & 1 & $1 \%$ & 3 & $2 \%$ & \\
\hline Grade 8-12 & 10 & $5 \%$ & 12 & $7 \%$ & \\
\hline High school & 8 & $5 \%$ & 19 & $11 \%$ & \\
\hline College work & 88 & $52 \%$ & 114 & $67 \%$ & \\
\hline College Graduate & 33 & $19 \%$ & 16 & $9 \%$ & \\
\hline Graduate Degree & 30 & $18 \%$ & 6 & $4 \%$ & \\
\hline Type of Job & & & & & .001 \\
\hline None & 49 & $29 \%$ & 91 & $54 \%$ & \\
\hline Clerical/Manual & 23 & $14 \%$ & 21 & $12 \%$ & \\
\hline Service/Sales & 41 & $24 \%$ & 30 & $18 \%$ & \\
\hline Business/Technical & 16 & $9 \%$ & 4 & $2 \%$ & \\
\hline Professional & 27 & $16 \%$ & 18 & $11 \%$ & \\
\hline Other & 14 & $8 \%$ & 6 & $4 \%$ & \\
\hline
\end{tabular}


Table 1 (Continuation)

Demographics for Whites and Minorities

\begin{tabular}{|c|c|c|c|c|c|}
\hline \multirow[t]{2}{*}{ Variable } & \multicolumn{2}{|c|}{ White } & \multicolumn{2}{|c|}{ Minority } & \multirow{2}{*}{$\begin{array}{l}\text { Chi square/ } \\
\text { t distribution }\end{array}$} \\
\hline & $\mathrm{n}$ & percent & $\mathrm{n}$ & percent & \\
\hline Marital Status & & & & & .065 \\
\hline Single & 98 & $58 \%$ & 119 & $70 \%$ & \\
\hline Married & 19 & $11 \%$ & 19 & $11 \%$ & \\
\hline Separated/Divorced & 45 & $26 \%$ & 27 & $16 \%$ & \\
\hline Widowed & 8 & $5 \%$ & 5 & $3 \%$ & \\
\hline Type of Sex Partner & & & & & .218 \\
\hline Just men & 158 & $93 \%$ & 154 & $90 \%$ & \\
\hline Mostly with men & 3 & $1 \%$ & 10 & $6 \%$ & \\
\hline Men \& Women & 1 & $1 \%$ & 2 & $1 \%$ & \\
\hline Mostly with women & 1 & $1 \%$ & 1 & $1 \%$ & \\
\hline Always with women & 7 & $4 \%$ & 3 & $2 \%$ & \\
\hline Number of Children & & & & & .016 \\
\hline None & 105 & $62 \%$ & 77 & $45 \%$ & \\
\hline 1 or 2 & 43 & $25 \%$ & 69 & $41 \%$ & \\
\hline 3 or more & 22 & $13 \%$ & 24 & $14 \%$ & \\
\hline Number of & & & & & \\
\hline Pregnancies & & & & & .003 \\
\hline None & 73 & $43 \%$ & 56 & $33 \%$ & \\
\hline 1 or 2 & 59 & $35 \%$ & 50 & $29 \%$ & \\
\hline 3 or 4 & 25 & $15 \%$ & 38 & $22 \%$ & \\
\hline 4 or more & 13 & $7 \%$ & 26 & $16 \%$ & \\
\hline Living Arrangement & & & & & .621 \\
\hline No & 105 & $62 \%$ & 102 & $60 \%$ & \\
\hline Sometimes & 26 & $15 \%$ & 22 & $13 \%$ & \\
\hline Yes & 39 & $23 \%$ & 46 & $27 \%$ & \\
\hline Regular Sex Partner & & & & & .143 \\
\hline No & 52 & $31 \%$ & 40 & $24 \%$ & \\
\hline Yes & 118 & $69 \%$ & 130 & $76 \%$ & \\
\hline
\end{tabular}


Table 2

Condom Stage Distributions

$\begin{array}{lll}\text { Variable } & \text { n } & \text { Percent }\end{array}$

Condom Use in Last 30 days

Always

47

$14 \%$

Never

148

$44 \%$

Sometimes

$20 \%$

Condom Stage of Change

Precontemplation

Contemplation

65

$20 \%$

Preparation

47

$14 \%$

Action

21

$6 \%$

Maintenance

52

$16 \%$

\section{White Subsample (170)}

Condom Stage of Change

Precontemplation

86

$53 \%$

Contemplation

29

Preparation

16

$18 \%$

Action

8

Maintenance

24

$10 \%$

$5 \%$

$14 \%$

Minority Subsample (170)

Condom Stage of Change

Precontemplation

62

$37 \%$

Contemplation

36

$21 \%$

Preparation

31

$18 \%$

Action

13

$8 \%$

Maintenance

28

$16 \%$ 
Table 3

Descriptive Statistics and Cronbach's Alphas on all Scales

Variable

$\underline{M}$

$\underline{\mathrm{SD}}$

Cronbach's Alpha

Decisional Balance for Total

Sample $(n=340)$

Pros

3.94

.73

Cons

2.18

.83

.76

.78

Decisional Balance for White

Subsample $(n=170)$

Pros

Cons

2.22

.88

.72

.80

.85

.81

Decisional Balance for Minority

Subsample $(n=170)$

Pros

3.94

.79

.74

Cons

2.13

.80

.70

.75

Self-Efficacy for Total Sample

$(\mathrm{n}=340)$

Confidence

$3.37 \quad 1.28$

.91

Self-Efficacy for White Subsample

( $\mathrm{n}=170$ )

Confidence

Self-Efficacy for Minority

Subsample $(n=170)$

Confidence 
Table 4

Intercorrelations Between Decisional Balance Pro Variables for Minority Subsample

Variables

1

2

3

4

56

7

8

1. Build trust in relationship $\quad 1.00$

2. Feel more responsible

$.273 \quad 1.00$

3. Sex will feel safer

$.226 \quad .401 \quad 1.00$

$\begin{array}{lllll}\text { 4. Less worry of pregnancy } & .006 & .053 & .336 & 1.00\end{array}$

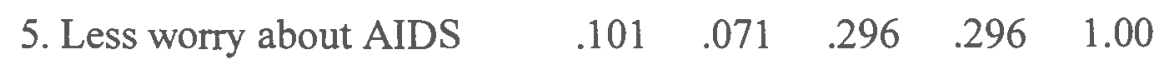

6. Build respect

$\begin{array}{llllll}.351 & .282 & .268 & .171 & .191 & 1.00\end{array}$

7. Protect my partner

$\begin{array}{lllllll}.378 & .294 & .358 & .088 & .235 & .424 & 1.00\end{array}$

8. Condoms are available $\begin{array}{llllllll}.255 & .223 & .229 & .150 & .119 & .431 & .182 & 1.00\end{array}$ 
Table 5

Intercorrelations Between Decisional Balance Con Variables for Minority Subsample

Variables

1

2

3

4

5

6

7

8

1. A lot of trouble

1.00

2. Sex is planned

$.254 \quad 1.00$

3. Partner might get angry

$\begin{array}{lll}.236 & .203 \quad 1.00\end{array}$

4. Sex is less exciting

$\begin{array}{llll}.406 & .194 & .220 & 1.00\end{array}$

5. Partner might refuse sex

$\begin{array}{lllll}.275 & .125 & .448 & .440 & 1.00\end{array}$

6. Partner might not like it

$\begin{array}{llllll}.233 & .145 & .385 & .442 & .549 & 1.00\end{array}$

7. Partner might make fun

$\begin{array}{lllllll}.233 & .164 & .443 & .242 & .299 & .400 & 1.00\end{array}$

$\begin{array}{lllllllll}\text { 8. Partner thinks I'm unfaithful } & .110 & .048 & .305 & .258 & .397 & .285 & .298 & 1.00\end{array}$ 
Table 6

Transtheoretical Variables and Minorities

Stage Distribution

$\begin{array}{llll}\text { Stage } & \text { Ethnicity } & \text { Percent }\end{array}$

Precontemplation

White

African Americans

Native Americans

Asian Americans

Hispanic Americans

Other-non whites

Contemplation

Preparation

Action

Maintenance
White

African Americans

Native Americans

Asian Americans

Hispanic Americans

Other-non whites

White

African Americans

Native Americans

Asian Americans

Hispanic Americans

Other-non whites

White

African Americans

Native Americans

Asian Americans

Hispanic Americans

Other-non whites

White

African Americans

Native Americans

Asian Americans

Hispanic Americans

Other-non whites
86

26

4

9

13

10

29

17

3

5

4

7

16

18

0

7

3

3

$53 \%$

$34 \%$

$40 \%$

$36 \%$

$45 \%$

$35 \%$

$18 \%$

$22 \%$

$30 \%$

$20 \%$

$14 \%$

$24 \%$

$10 \%$

$23 \%$

$0 \%$

$28 \%$

$10 \%$

10

$5 \%$

$5 \%$

$10 \%$

$8 \%$

$7 \%$

$14 \%$

24

$15 \%$

12

$16 \%$

$20 \%$

$8 \%$

$24 \%$

$17 \%$ 
Table 7

The Pros of Decisional Balance

$\begin{array}{lllll}\text { Condom Stage } & \text { Ethnicity } & \underline{M} & \underline{S D} & \mathrm{n}\end{array}$

\begin{tabular}{|c|c|c|c|c|}
\hline Precontemplation & White & 47.60 & 12.34 & 86 \\
\hline & African American & 45.09 & 11.26 & 26 \\
\hline & Native American & 45.46 & 11.83 & 4 \\
\hline & Asian American & 51.57 & 6.05 & 9 \\
\hline & Hispanic American & 46.47 & 10.74 & 13 \\
\hline & Other non-whites & 46.54 & 10.24 & 10 \\
\hline Contemplation & White & 49.81 & 8.89 & 29 \\
\hline & African American & 52.76 & 8.07 & 17 \\
\hline & Native American & 45.74 & 10.53 & 3 \\
\hline & Asian American & 51.64 & 12.83 & 5 \\
\hline & Hispanic American & 46.99 & 5.54 & 4 \\
\hline & Other non-whites & 53.95 & 7.86 & 7 \\
\hline Preparation & White & 53.27 & 7.15 & 16 \\
\hline & African American & 51.99 & 8.62 & 18 \\
\hline & Native American & & & \\
\hline & Asian American & 51.60 & 3.95 & 7 \\
\hline & Hispanic American & 44.24 & 25.54 & 3 \\
\hline & Other non-whites & 53.73 & 2.60 & 3 \\
\hline Action & White & 53.73 & 6.00 & 8 \\
\hline & African American & 46.99 & 3.77 & 4 \\
\hline & Native American & 62.72 & & 1 \\
\hline & Asian American & 55.98 & 3.18 & 2 \\
\hline & Hispanic American & 53.73 & 4.24 & 2 \\
\hline & Other non-whites & 56.36 & 3.75 & 4 \\
\hline Maintenance & White & 53.42 & 6.57 & 24 \\
\hline & African American & 52.98 & 7.44 & 12 \\
\hline & Native American & 35.75 & .000 & 2 \\
\hline & Asian American & 56.73 & 2.12 & 2 \\
\hline & Hispanic American & 55.66 & 5.85 & 7 \\
\hline & Other non-whites & 51.34 & 6.84 & 5 \\
\hline
\end{tabular}


Table 8

The Cons of Decisional Balance

Condom Stage

Ethnicity

$\underline{\mathrm{M}}$

$\underline{\mathrm{SD}}$

n

Precontemplation

White

51.36

9.61

86

African American

50.05

8.25

26

Native American

58.09

9.34

Asian American

46.72

8.40

4

Hispanic American

49.06

8.90

9

Other non-whites

53.94

5.87

13

10

Contemplation

White

African American

51.80

10.74

29

Native American

53.58

10.91

17

Asian American

45.38

6.98

3

Hispanic American

50.62

Other non-whites

51.30

9.52

7.74

54.16

9.53

5

4

7

Preparation

White

African American

53.28

10.30

16

49.16

11.79

18

Native American

Asian American

Hispanic American

46.60

5.76

13.08

Other non-whites

43.37

5.45

7

52.43

3

Other non-whites

Action

White

African American

Native American

Asian American

Hispanic American

Other non-whites

Maintenance

White
African American
Native American
Asian American
Hispanic American
Other non-whites

46.96

10.89

6.21

37.33

37.33

40.35

55.07

44.31

44.38

37.33

44.12

47.47

44.27

$\begin{array}{cc}6.21 & 4 \\ & 1 \\ .000 & 2 \\ 4.27 & 2 \\ 15.86 & 4\end{array}$

7.88

24

6.58

12

.000

2

3.20

2

13.30

7

11.53

5 
Table 9

Self-Efficacy

$\begin{array}{lllll}\text { Condom Stage } & \text { Ethnicity } & \underline{\mathrm{M}} & \underline{\mathrm{SD}} & \mathrm{n}\end{array}$

$\begin{array}{llccc}\text { Precontemplation } & \text { White } & 45.86 & 10.20 & 86 \\ & \text { African American } & 43.07 & 10.38 & 26 \\ & \text { Native American } & 43.17 & 13.16 & 4 \\ & \text { Asian American } & 57.07 & 3.59 & 9 \\ & \text { Hispanic American } & 46.18 & 6.10 & 13 \\ & \text { Other non-whites } & 43.56 & 9.09 & 10\end{array}$

Contemplation

White

48.84

7.81

29

African American

51.68

11.07

17

Native American

51.43

11.75

54.38

8.22

52.95

13.01

51.18

6.04

3

Asian American

Hispanic American

Other non-whites

Preparation

White

48.96

8.55

16

African American

50.63

11.33

18

Native American

Asian American

53.60

4.99

7

Hispanic American

48.39

15.36

45.35

10.85

3

Other non-whites

56.53

6.49

9.72

African American

51.97

58.81

59.46

Asian American

Hispanic American

58.81

Other non-whites

55.55

58.43

60.77

56.21

58.81

9.72

4.61

5.53

8.55

3

Maintenance

White
African American
Native American
Asian American
Hispanic American
Other non-whites

53.41

59.85

4.60

3.45

.000

3.69

8.69

3.50

8

4

1

2

2

4 
Table 10

ANOVA Summaries for Condom Stages of Change, Pros, Cons, Self-Efficacy, and Ethnicity

\section{One-way ANOVAs}

1. IV - Stage DV-pros

2. IV - Stage DV-cons

3. IV - Stage DV-Self-efficacy
$340 \quad \underline{F}(5,334)=5.13 \quad .08 \quad .001$

$340 \quad \underline{F}(5,334)=4.72 \quad .07 \quad .001$

$340 \quad \underline{F}(5,334)=17.38 \quad .20 \quad .001$

Two-way ANOVAs

1. Main effects \& interactions for pros:

IV 1-Ethnicity

IV 2-Stage

IV 1 - Ethnicity and IV 2- Stage

2. Main effects \& interactions for cons:

IV 1-Ethnicity

IV 2-Stage

IV 1-Ethnicity, IV 2- Stage
$340 \quad \underline{F}(1,329)=.130 \quad .08 \quad .719$

$340 \quad \underline{F}(5,329)=5.23 \quad .08 \quad .001$

$340 \quad \underline{F}(4,329)=.316 \quad .08 \quad .867$

$340 \quad \underline{F}(1,329)=.142 \quad .08 \quad .707$

$340 \quad \underline{\mathrm{F}}(5,329)=4.65 \quad .08 \quad .001$

$340 \quad \underline{F}(4,329)=.728 \quad .08 \quad .573$

3. Main effects \& interactions for self-efficacy

IV 1-Ethnicity

IV 2-Stage

IV 1- Ethnicity, IV 2- Stage
$340 \quad \mathrm{~F}(1,329)=.422$

$340 \quad \underline{F}(5,329)=17.02$

$340 \underline{\mathrm{F}}(4,329)=.460$
$.21 \quad .516$

$.21 \quad .001$

$.21 \quad .765$ 
Table 11

Means, Standard Deviations and Sample Size of the Pros, Cons, and Self-efficacy by Condom Stage of Change

\begin{tabular}{|c|c|c|c|c|}
\hline Variable & Condom Stage & $\underline{\mathrm{M}}$ & $\underline{\mathrm{SD}}$ & $\mathrm{N}$ \\
\hline \multirow[t]{5}{*}{ Pros } & Precontemplation & 47.18 & 11.51 & 340 \\
\hline & Contemplation & 50.81 & 8.75 & 340 \\
\hline & Preparation & 51.98 & 8.92 & 340 \\
\hline & Action & 53.59 & 5.76 & 340 \\
\hline & Maintenance & 52.87 & 7.26 & 340 \\
\hline \multirow[t]{5}{*}{ Cons } & Precontemplation & 51.00 & 9.10 & 340 \\
\hline & Contemplation & 52.10 & 10.10 & 340 \\
\hline & Preparation & 50.02 & 10.40 & 340 \\
\hline & Action & 48.47 & 11.68 & 340 \\
\hline & Maintenance & 44.47 & 8.49 & 340 \\
\hline \multirow[t]{5}{*}{ Self-efficacy } & Precontemplation & 45.85 & 10.02 & 340 \\
\hline & Contemplation & 50.63 & 8.97 & 340 \\
\hline & Preparation & 50.02 & 9.70 & 340 \\
\hline & Action & 56.08 & 6.94 & 340 \\
\hline & Maintenance & 58.36 & 5.23 & 340 \\
\hline
\end{tabular}


Table 12

Standard Multiple Regressions Results for Prediction of Condom Stage of Change

Variable

1. Using Total Sample $(n=340)$

PROS

CONS

Self- Efficacy

2. Using White Subsample $(n=170)$

PROS

CONS

Self- Efficacy

3. Using Minority Subsample $(n=170)$

PROS

CONS

Self- Efficacy $\begin{array}{lllll}\text { B } & \beta & \mathrm{R} & \mathrm{R} 2 & \underline{\mathrm{P}}\end{array}$

$.44 \quad .20 \quad .001$

$133.1 \quad .089$

.09

$.02 \quad-.112$

.03

$539.0 \quad .361$

.001

$\begin{array}{lll}.43 & .17 & .001\end{array}$

102. .07

.325

$\begin{array}{ll}.01 & -.092\end{array}$

.220

$560 . \quad .37$

.001

$\begin{array}{lll}.45 & .20 & .001\end{array}$

204. .13

.10

$\begin{array}{ll}-.02 & -.14\end{array}$

.07

472. .33

.001 
Table 13

Hierarchical Multiple Regression Results for Prediction of Condom Stage of Change from Demographic and Transtheoretical Variables (Regression \# 1)

Variable

B

$\beta$

$\mathrm{R}$

$\mathrm{R} 2$

$\underline{\mathrm{P}}$

Using Total Sample $(n=340)$

Step 1

Age

Education

Job

Income

Marital Status

Sex Partner

Living Arrangement

Relationship Length

Ethnicity

Number of kids

Number of pregnancies

$\begin{array}{lllll} & & .33 & .11 & .001 \\ .01 & -.07 & & & .459 \\ .08 & -.05 & & & .444 \\ 822.0 & .08 & & & .234 \\ -.30 & -.18 & & & .014 \\ -.17 & -.10 & & & .195 \\ -.45 & -.13 & & & .038 \\ -.163 & -.09 & & & .158 \\ .0003 & -.001 & & & .989 \\ .144 & .05 & & & .436 \\ .09 & -.08 & & & .468 \\ .11 & .15 & & & .141\end{array}$

.52

.28

.001

.365

.063

.063

.011

.653

.069

.232

.953

.836

.955

.310

.215

.013

.001 
Table 14

Hierarchical Multiple Regression Results for Prediction of Condom Stage of Change from Demographic and Transtheoretical Variables (Regression \# 2)

Variable

B

$\beta$

$\mathrm{R}$

$\mathrm{R} 2$

$\underline{\mathrm{P}}$

Using White Subsample $(\mathrm{n}=170)$

Step 1

Age

Education

Job

Income

Marital Status

Sex Partner

Living Arrangement

Relationship Length

Number of kids

Number of pregnancies

Step 2

Age

Education

Job

Income

Marital Status

Sex Partner

Living Arrangement

Relationship Length

Number of kids

Number of pregnancies

Pros

Cons

Self-efficacy
$.01 \quad-.06$

$\begin{array}{ll}.07 & -.05\end{array}$

$922.3 \quad .08$

$\begin{array}{ll}-.26 & -.17\end{array}$

$-.19 \quad-.11$

$-.51 \quad-.15$

$538.1 \quad .03$

$\begin{array}{ll}.02 & -.09\end{array}$

$\begin{array}{ll}.05 & -.04\end{array}$

$623.9 \quad .07$

$\begin{array}{ll}.02 & -.14\end{array}$

$-.14 \quad-.10$

$.15 \quad .14$

$-.24 \quad-.16$

$\begin{array}{ll}.09 & -.05\end{array}$

$\begin{array}{ll}-.39 & -.12\end{array}$

$473.8 \quad .03$

$\begin{array}{ll}.02 & -.08\end{array}$

$612.8 \quad .05$

$529.8 \quad .06$

6509. .04

$.02 \quad-.11$

$640.8 \quad .41$
.31

.10

.158

.691

.618

.392

.111

.351

.103

.780

.466

.818

.625

.55

.30

.001

.284

.285

.131

.099

.618

.166

.787

.507

.740

.646

.579

.185

.001 
Table 15

Hierarchical Multiple Regression Results for Prediction of Condom Stage of Change from Demographic and Transtheoretical Variables (Regression \# 3)

Variable

B

$\beta$

$\mathrm{R}$

R2 $\quad \underline{P}$

Using Minority Subsample $(\mathrm{n}=170)$

Step 1

Age

Education

Job

Income

Marital Status

Sex Partner

Living Arrangement

Relationship Length

Number of kids

Number of pregnancies

Step 2

Age

Education

Job

Income

Marital Status

Sex Partner

Living Arrangement

Relationship Length

Number of kids

Number of pregnancies

Pros

Cons

Self-efficacy

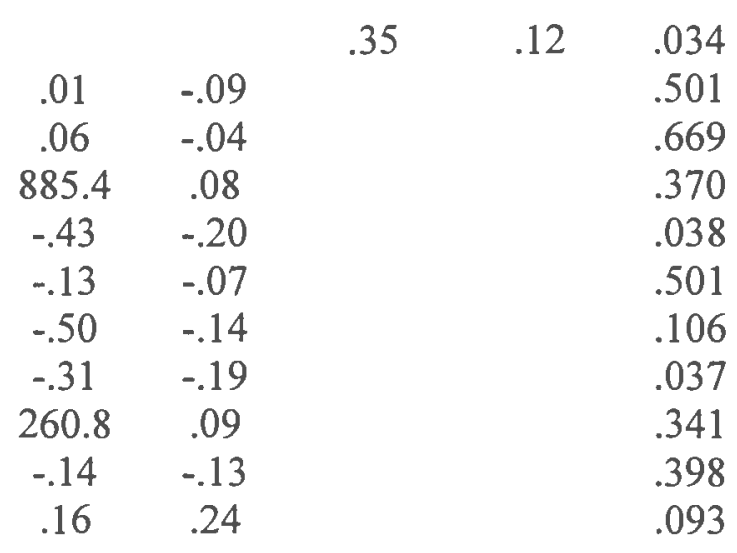

.52

.27

.001

$.004 \quad-.03$

$\begin{array}{ll}-21 & -.13\end{array}$

$\begin{array}{ll}780.0 & .07\end{array}$

.823

.131

.393

$\begin{array}{ll}-.37 & -.18\end{array}$

.051

$194.1 \quad .01$

$\begin{array}{ll}-.43 & -.12\end{array}$

.914

.131

$\begin{array}{ll}-.237 & -.14\end{array}$

.089

$234.4 \quad .08$

.356

$\begin{array}{ll}.09 & -.08\end{array}$

.571

$.11 \quad .16$

.239

$200.9 \quad .13$

.130

$\begin{array}{ll}.03 & -.17\end{array}$

.042

$04.4 \quad .28$ 


\section{Figure Captions}

Figure 1. Ethnic distribution of condom stage.

Figure 2. Ethnic distribution of pros within each condom stage.

Figure 3. Ethnic distribution of cons within each condom stage.

Figure 4. Ethnic distribution of self-efficacy within each condom stage.

Figure 5. Means for pros and cons across the condom stages.

Figure 6. Means for self-efficacy across the condom stages. 


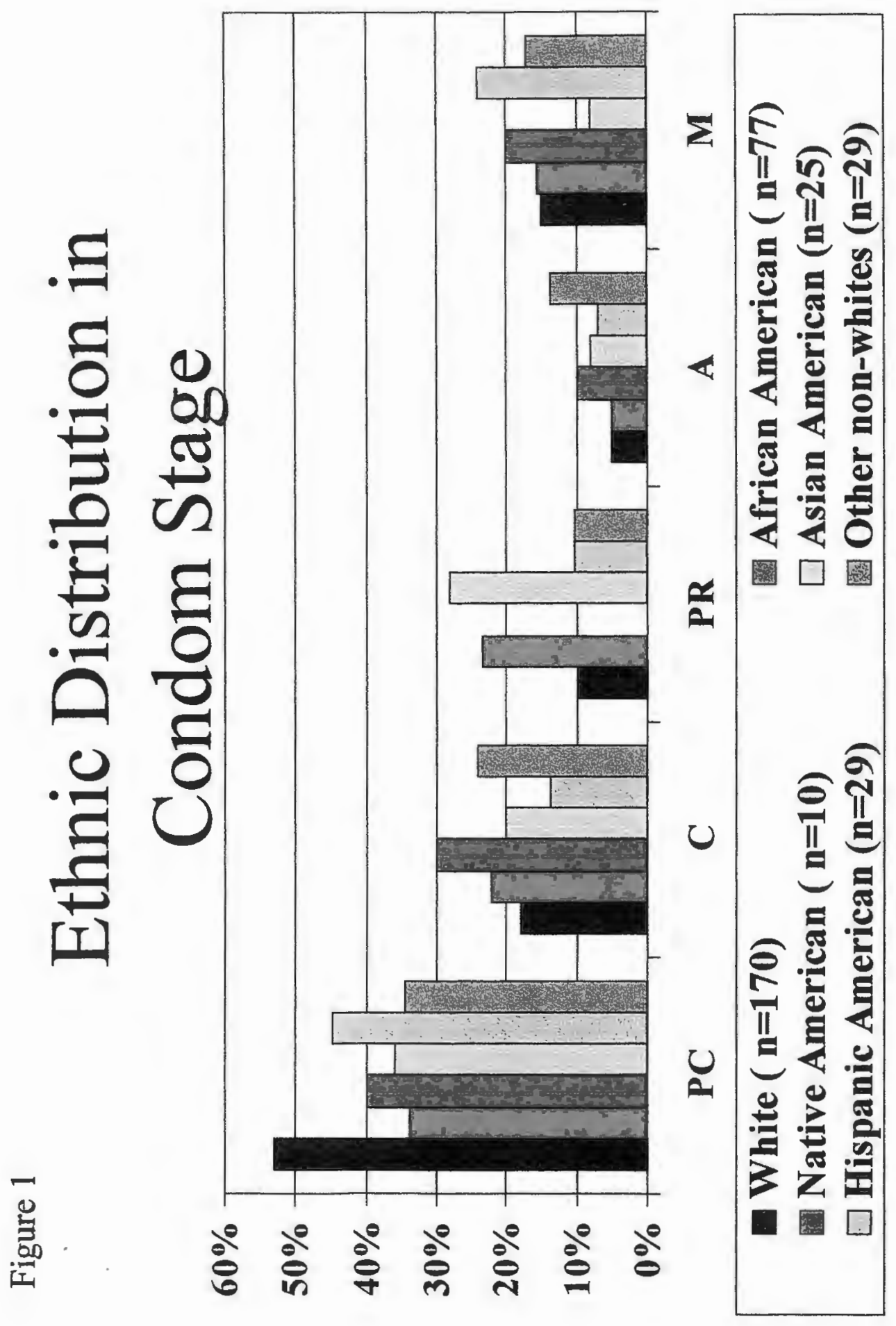




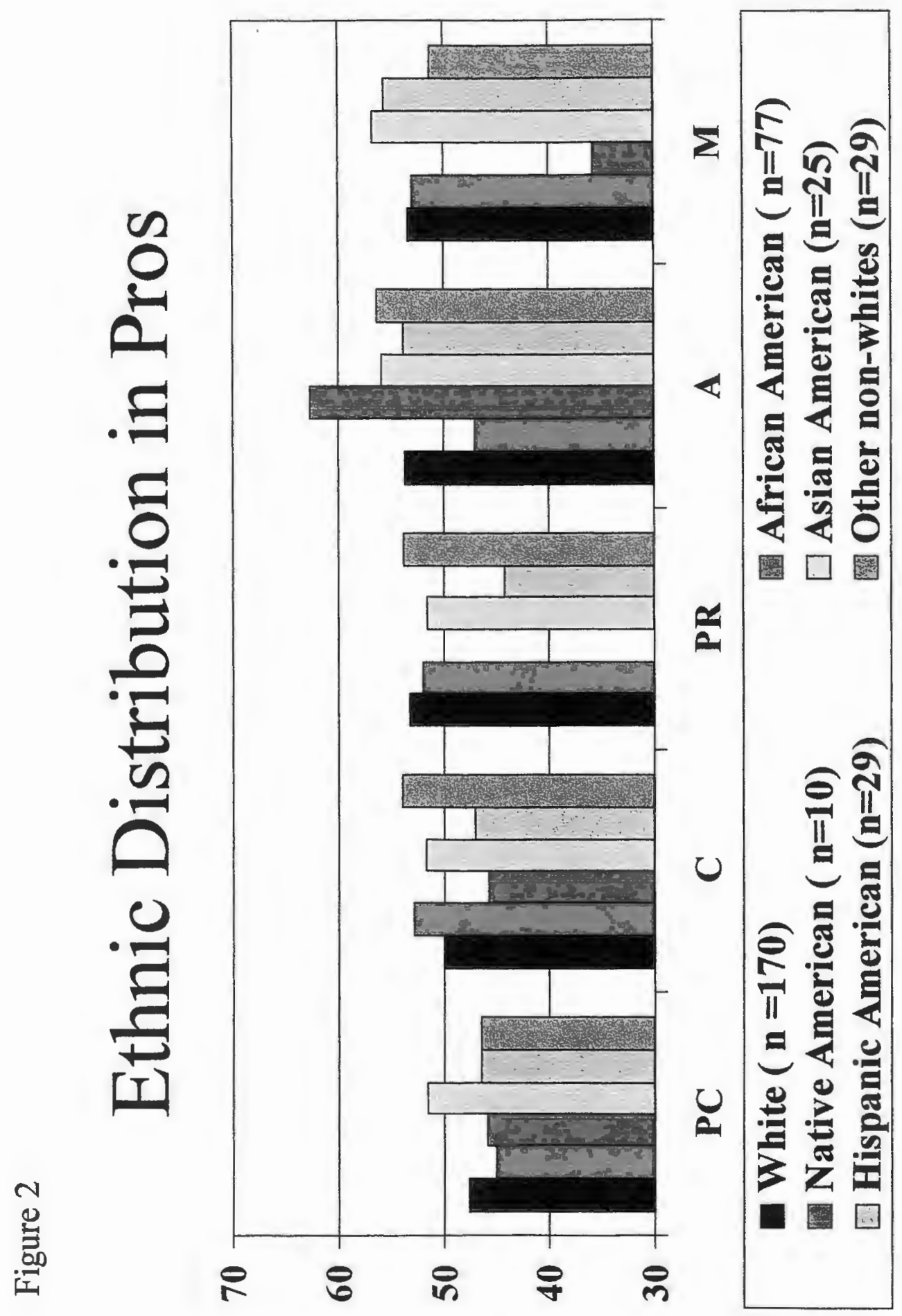




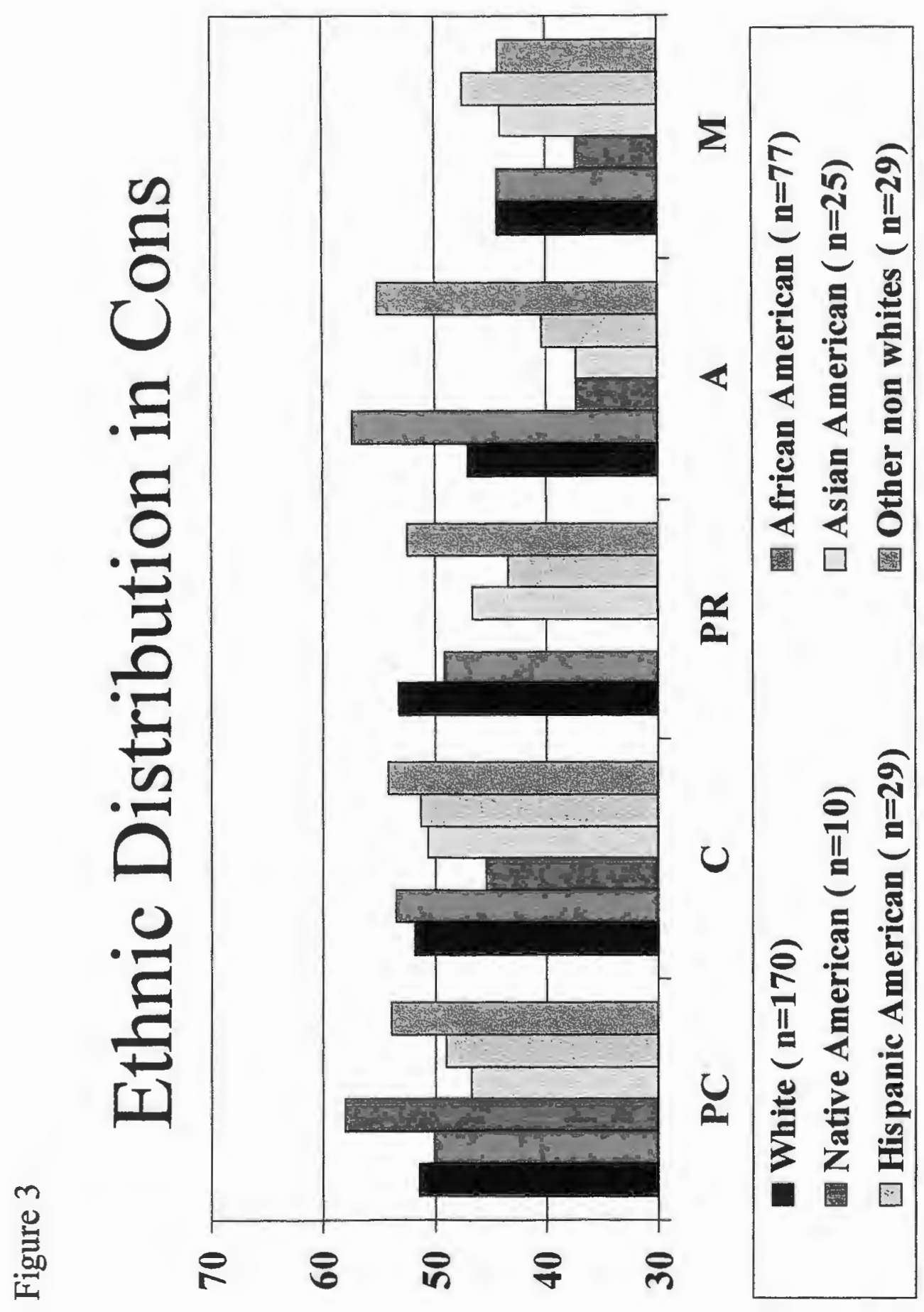




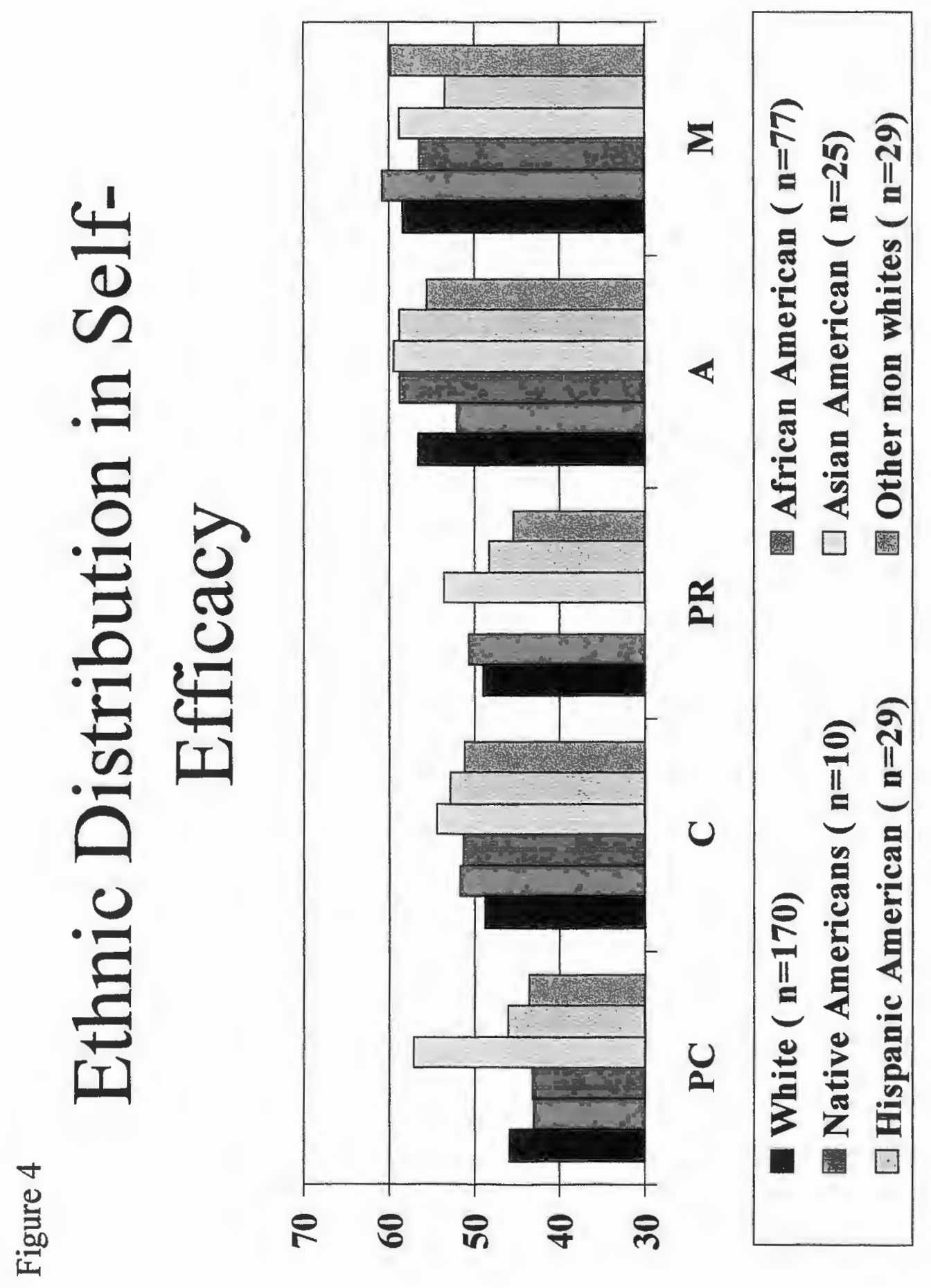




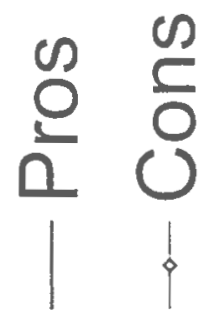

0
$\frac{1}{10}$
10

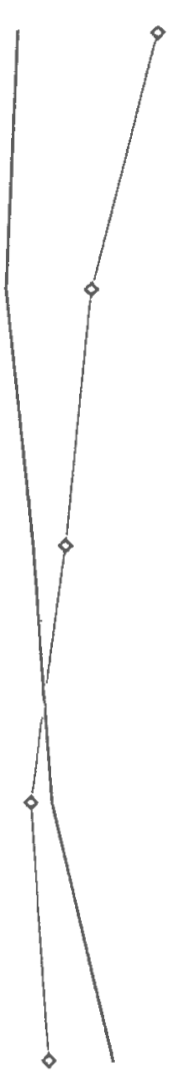

$\Sigma$

$\varangle$

$\frac{6}{6}$

(a)

0

$\frac{\alpha}{\alpha}$

0

$\cup$

온

$\begin{array}{lllll}0 & 0 & 0 & 0\end{array}$

sueow 


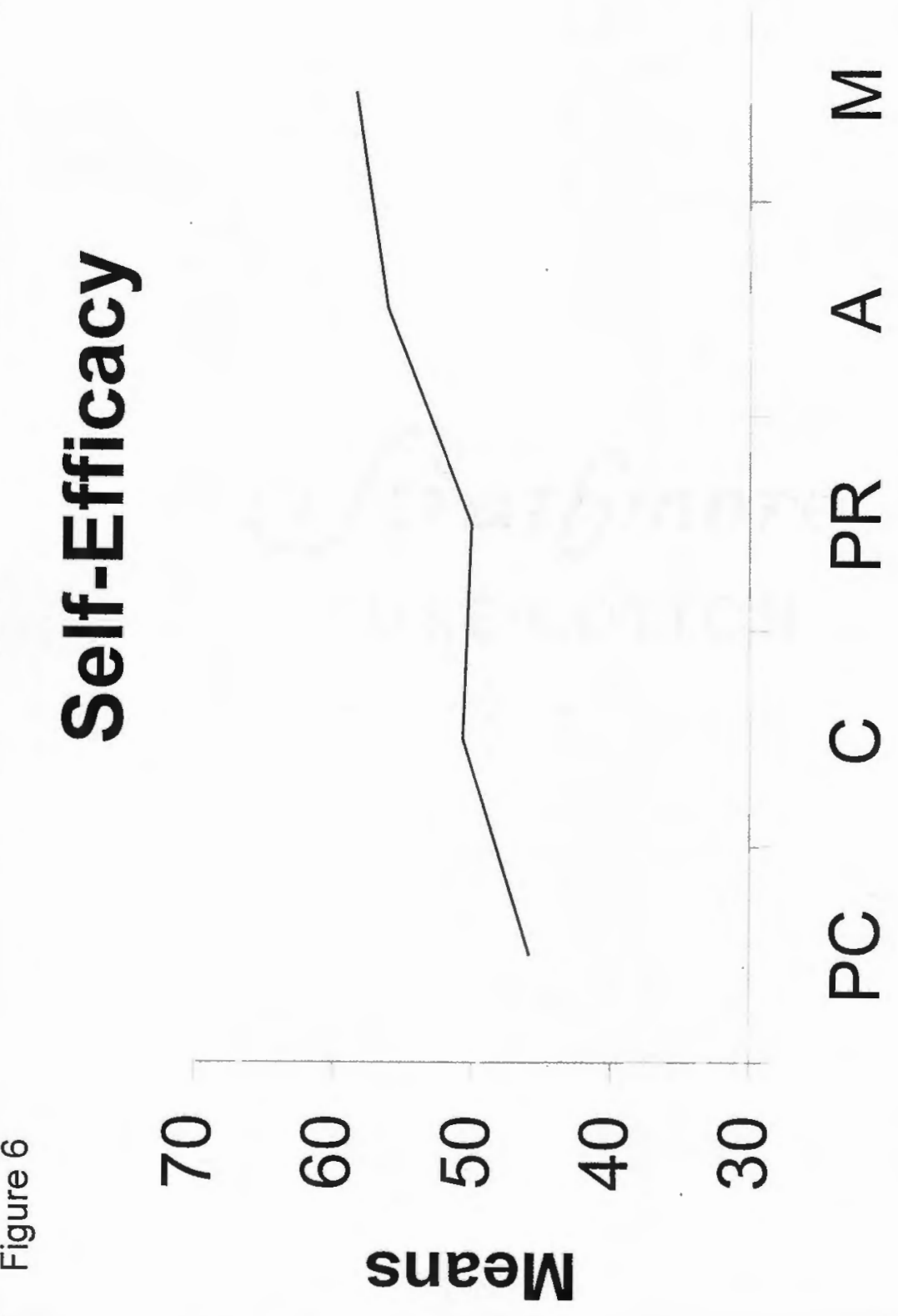




\section{Bibliography}

Amaro, H. (1988). Considerations for prevention of HIV infection among Hispanic women. Psychology of Women Quarterly, 12, 429-443.

Amaro, H. (1995). Love, sex, and power. American Psychologists, 50(6), 437-447.

Bandura, A. (1977). Self-efficacy: Toward a unifying theory of behavioral change. Psychological Review, 84(2), 191-215.

Bandura, A. Social cognitive theory and exercise of control over HIV infection. In:

DiClimente, R. J., Peterson J. L., editors, Preventing AIDS: theories and methods of behavioral interventions. New York: Plenum Press, 25-59.

Battle, C.U. (1986). Women and AIDS. Journal of Medical Women's Association, 41(2), $37-61$.

Bell, R. A., Alcalay, R. (1997). The impact of the wellness guide/guia on Hispanic women's well-being-related knowledge, efficacy, beliefs, and behaviors: The mediating role of acculturation. Health Education and Behavior, 24 (2) 326-343.

Bowen, A. M., \& Trotter, R. (1995). HIV risk in intravenous drug users and crack cocaine smokers: predicting stage of change for condom use. Journal of Consulting and Clinical Psychology, 63, 238-248.

Catania, J. A., Kegeles, S. M., \& Coates, T. J. (1990). Towards an understanding of risk behavior: an AIDS Risk reduction Model (ARRM). Health Education Quarterly, $17,53-72$. 
Catania, J. A., Coates, T. J., Peterson, J., Dolciri, M. M., Kegeles, S., Siegel, D., Golden, E., Thompson Fullilove, M. (1993). Changes in condom use among African American, Hispanic, and White heterosexuals in San Francisco: The amen cohort survey. The Journal of Sex Research, 30 (2), 121-128.

Centers for Disease Control and Prevention. (1992). Division of STD/HIV Prevention Annual Report 1991 (Vol. 13).

Centers for Disease Control and Prevention. (1993). Update: Mortality attributable to HIV infection among persons aged 25-44 years - United States. 1991 and 1992. Morbidity and Mortality Weekly Report. 42(45), 869-872.

Centers for Disease Control and Prevention. (1994). Heterosexually acquired AIDSUnited States. 1993. Morbidity and Mortality Weekly report, 43(9). 155-160. Centers for Disease Control and Prevention. (1998). HIV: AIDS Surveillance Report (Vol. 10,2).

Centers for Disease Control and Prevention. (1999). HIV: AIDS Surveillance Report (Vol. 11,1).

Clark, H. H., \& Schober, M.F. (1992). Asking questions and influencing answers. In J. Tanur (Ed.), Questions about Questions: Inquiries into the Cognitive Bases of Surveys (pp.15-48). New York: Russell Sage.

DiClemente, C. C., Prochaska, J. O., \& Gibertini, M. (1985). Self-efficacy and the stages of self-change of smoking. Cognitive Therapy and Research, 9.(2), 181-200.

Evers, K. E., Harlow, L. L., Redding, C. A., \& Laforge, R. G. (1998). Longitudinal changes in stages of change for condom use in women. American Journal of Health Promotion, 13(1), 19-25. 
Evers, K., Laforge, R. G., \& Hạlow, L. L. (1996a). Predictors of positive and negative change in condom attitudes and behaviors in a longitudinal naturalistic study of high risk women. Paper presented at the $10^{\text {th }}$ Health Psychology Society Conference, Dublin, Ireland.

Evers, K., Saxon, S., Redding, C. A., Rossi, J. S., \& Lavesque, D. (1996b). Stages of condom use and process variables among sexually active young adults. Paper presented at the $4^{\text {th }}$ International Congress of behavioral Medicine, Washington, DC.

Flack, J. M., Amaro, H., Jenkins, W., Kunitz, S., Levy, J., Mixon, M., \& Yu., E. (1995). Panel I: Epidemiology of minority health. Health Psychology, 14 (7), 592-600. Gangakhedkar, R. R., Bentley, M. E., Divekar, A. D., Gadkari, D., Mehendale, S. M., Sheperd, M. E., Bollinger, R. C., \& Quinn, T. C. (1997). Spread of HIV infection in married monogamous women in India. Journal of American Association, 278, 2090-2092.

Galavotti, C., Cabral, R. J., Lansky, A., Grimley, D. M., Riley, G. E., \& Prochaska, J. O., (1995). Validation of measures of condom and other contraceptive use among women at risk for HIV infection and unintended pregnancy. Health Psychology, $\underline{14}(6), 570-578$.

Grimley, D. M., Prochaska, G. E., Prochaska, J. O., Velicer, W. F., Galavotti, C., Cabral, R. J., \& Lansky, A. (1996). Cross-validation of measures assessing decisional balance and self-efficacy for condom use. American Journal of Health Behavior, $\underline{20}(6), 406-416$. 
Grimley, D. M., Prochaska, J. O., Velicer, W. F., \& Prochaska, G. E. (1995).

Contraceptive and condom use adoption and maintenance: a stage paradigm approach. Health Education Quarterly, 22(1), 20-35.

Grimley, D. M., Riley, G. E., Bellis, J. M., \& Prochaska, J. O. (1993). Assessing the stages of change and decision-making for contraceptive use for the prevention of sexually transmitted diseases, and acquired immuno deficiency syndrome. $\underline{\text { Health }}$ Education Quarterly, 20(4), 455-470.

Grimley D., Riley, G. E., Prochaska, J. O., Redding, C. A., Ruggiero, L., Rossi, J. S., \& Velicer, W. F. (1992). The stages of change model and reproductive health in high risk populations. Technical report for Centers for Disease Control and Prevention, Contract Grant CSA-92-109.

Harlow, L. L., Prochaska, J. O., Redding, C. A., Rossi, J. S., Velicer, W. F., Snow, M. G., Schnell, D., Galavotti, C., O'reilly, K., \& Rhodes, F. (1999). Stages of condom use in a high HIV-risk sample. Psychology and Health, 14, 143-157.

Harlow, L.L., Morokoff, P.J., \& Quina, K. (1991). Predicting HIV-risky heterosexual behavior in women. University of Rhode Island, NIMH Grant MH47233.

Harlow, L. L., Rose, J. S., Morokoff, P. J., Quina, K., Mayer, K., Mitchell, K., \& Schnoll, R. (1998). Women with HIV sexual risk takers: related behaviors, interpersonal issues, and attitudes. Women's Health Research on Gender, Behavior, and Policy, $\underline{4}(4), 407-439$. 
Harlow, L. L., Quina, K., Morokoff, P. J., Rose, J. S., \& Grimley, D. M. (1993). HIV risk in women: a multifaceted model. Journal of Applied Biobehavioral Research, 1 , (1), 3-38.

Hobfoll, S. E., Gayle, J. A., Gruber, V., \& Levine, O. (1990). Anxiety's role in AIDS prevention. Anxiety Research, 3, 85-99.

Janis, I. L., Mann, L. (1977). Decision making: A psychological Analysis of Conflict, Choice and Commitment. New York: Free Press.

Kalichman, S. C., Hunter, T. L. \& Kelly, J. A. (1992). Perceptions of AIDS susceptibility among minority and nonminority women at risk for HIV infection. Journal of Consulting and Clinical Psychology, 60, 725-732.

Kline, A., Kline, E., \& Oken, E. (1992). Minority women and sexual choice in the age of AIDS. Social Science Medicine, 34, 447-457.

Land, H. (1994). AIDS and women of color. Families and Societies: The Journal of Contemporary Human Services, 1, 355-361.

Mays, V. M. \& Cochran, S.D. (1988). Issues in the perception of AIDS risk and risk reduction activities by African American and Hispanic/Latina women. American Psychologist, 43(11), 949-957.

Margillo, G. A., \& Imahori, T. T. (1998). Understanding safer sex negotiation in a group of low-income African American women. In N. L. Roth \& L. K. Fuller (Eds.), Women and AIDS: Negotiating Safer Practices, Care, and Representation. New York: Harrington Park Press. 
Newcomb, M. D., Wyatt, G. E., Romero, G. J., Tucker, M. B., Wayment, H. A., Vargas Carmona, J., Solis, B., \& Mitchell-Kernan, C. (1998). Acculturation, sexual risk taking, and HIV health promotion among Latinas. $\underline{\text { Journal of }}$ Counseling Psychology, 45, (4), 454-467.

Nyamathi, A., Bennett, R.N., Leake, B., Lewis, C., \& Flaskerud, R.N. (1993). AIDSrelated knowledge, perceptions, and behaviors, among impoverish minority women. American Journal of Public Health, 83(1), 65-71.

Phinney, J. S. (1996). When we talk about American ethnic groups, what do we mean? American psychologist, 51 (9) 918-927.

Prochaska, J. O., \& DiClemente, C. C. (1982). Transtheoretical therapy: Toward a more integrative model of change. Psychotherapy: Theory, research, and Practice, $\underline{19}(3), 276-288$.

Prochaska, J. O., \& DiClemente, C. C. (1983). Stages and processes of self-change of smoking: Toward an integrative model of change. Journal of Consulting and Clinical Psychology, 51(3), 390-395.

Prochaska, J. O. \& DiClemente, C. C. (1984). Self-change processes, self-efficacy, and decisional balance across five stages of smoking cessation. $\underline{\text { Advances in Cancer }}$ Control-1983. NY: Alan R. Liss.

Prochaska, J. O. \& DiClemente, C. C. (1985). Common processes of self-change in smoking, weight control, and psychological distress. In S. Shiffman \& T. Wills (Eds.), Coping and Substance Use: A Conceptual Framework. NY: Academic Press. 
Prochaska, J. O., DiClemente, C. C., Velicer, W. F., Ginpil, S., Norcross, J. C. (1985).

Predicting change in smoking status for self-changers. Addictive Behaviors, 10 . 395-406.

Prochaska, J.O., Harlow, L.L., Redding, C.A., Snow, M.G., Rossi, J.S., \& Velicer, W.F. (1990). Models of behavior change for condom use: Preliminary analyses in an AIDS-risking community sample (Contract \#0-4115-002). Atlanta, GA: Centers for Disease Control and Prevention.

Prochaska, J. O. Redding, C. A., \& Evers, K. (1997). The Transtheoretical Model. In K.

Glantz, F.M. Lewis, \& B.K. Rimer (Eds), Health Behavior and Health Education: Theory, research, and Practice. San Francisco, CA: Jossey-Bass.

Prochaska, J. O., Redding, C. A., Harlow, L. L., Rossi, J. S., \& Velicer, W. F. (1994a).

The Transtheoretical model of change and HIV prevention: a review. Education Quarterly, 21,(4), 471-486.

Prochaska, J. O., \& Velicer, W. F. (1997). The Transtheoretical model of health behavior change. American Journal of Health Promotion, 12(1), 38-48.

Prochaska, J. O., Velicer, W. F., Rossi, J. S., Goldstein, M. G., Marcus, B. H., Rakowski, W., Fore, C., Harlow, L. L., Redding, C. A., Rosenbloom, D., \& Rossi, S. (1994b). Stages of change and decisional balance for 12 problem behaviors. Health Psychology.13,(1), 39-46.

Raffaelli, M., \& Suarez-Al-Adam (1998). Reconsidering the HIV/AIDS Prevention Needs of Latino Women in the United States. In N. L. Roth \& L. K. Fuller (Eds.), Women and AIDS: Negotiating Safer Practices, Care, and Representation. New York: Harrington Park Press. 
Redding, C. A., \& Rossi, J. S. (1993 Suppl). The processes of safer sex adoption. Annals of Behavior Medicine, 15:S106 (Abstract).

Redding, C. A., \& Rossi, J. S. (1998). Testing a model of situational self-efficacy for safer sex among college students: stage of change and gender-based differences. Psychology and Health. 1-20.

Redding, C. A., Rossi, J. S., Velicer, W. F., \& Prochaska, J. O. (1989). The pros and cons of safer sex: a measurement model. Paper presented at the $97^{\text {th }}$ annual convention of the American Psychological Association, New Orleans, Louisiana,

Riley, G. E., Grimley, D. M., Prochaska, J. O., Redding, C. A., Ruggiero, L., Velicer, W. F., Rossi, J. S., Galavotti, C., \& Cabral, R. J. (1993). Self-efficacy for contraceptive and condom use in women at risk for HIV infection or transmission. Paper presented at $101^{\text {st }}$ annual meeting of the American Psychological Association, Toronto, Canada.

Rogler, L. H., Cortes, D. E., \& Malgady, R. G. (1991). Acculturation and mental health status among Hispanics: Convergence and new directions for research. American Psychologist, 46, (6), 585-597.

Rosenstock, I. M., Strecher V. J., \& Becker, M. H. (1994). The Health Belief Model and HIV risk behavior change. In: DiClemente R., Peterson, J., editors, Preventing AIDS: theories and methods of behavioral interventions. New York: Plenum Press, 5-24. 
Sikkema, K. J., Heckman, T.G., Kelly, J. A., Anderson, E. S., Winett, R. A., Solomon, L. J., Wagstaff, D. A., Roffman, R. A., Perry, M .J., Cargill, V., Crumble, D. A., Wayne Fuqua, R., Norman, A. D., \& Mercer, M. B. (1996). HIV risk behaviors among women living in low-income, inner-city housing developments. American Journal of Public Health, 86,(8), 1123-1127.

Simoni, J. M., Mason, H. R. C., Marks, G., Ruiz, M. S., Reed, D., \& Richardson, J. L. (1995). Women's disclosure of HIV infection: Rates reasons, and reactions. Journal of Consulting and Clinical Psychology, 63, 474-478.

Tabachinich, B. G., \& Fidell, L. S. (1996). Using Multivariate Statistics (3 ${ }^{\text {rd }}$ Edition). New York: Harper Collins.

Van Oss Marin, B., Tshann, J. M., Gomez, C. A., \& Gregorich, S. (1998). Self-efficacy to use condoms in unmarried Latino adults. American Journal of Community Psychology, 26,(1), 19-53.

Velicer, W. F., DiClemente, C. C., Prochaska, J. O., \& Brandenburg, N. (1985).

Decisional balance measure for assessing and predicting smoking status. Journal of Personality and Social Psychology, 48.(5), 1279-1289.

Velicer, W. F., DiClemente, C. C., Rossi, J. S., \& Prochaska, J. O. (1990). Relapse situations and self-efficacy: An integrative model. Addictive Behaviors, 15, 271283.

Waters, M., \& Eschabach, K. (1995). Immigration and ethnic and racial inequality in the United States. Annual Review of Sociology, 21, 419-446.

Wilcox, N. S., Prochaska, J. O., Velicer, W. F., and DiClemente, C. C. (1985). Subject 
characteristics as predictors of self-change in smoking. Addictive Behaviors, 10 , 407-421.

Wingwood, G. M., \& DiClemente, R. (1998). Pattern influences and gender related factors associated with noncondom use among young adult African American women. American journal of Community Psychology, 26,(1), 23-29. 